\title{
O Estado da Arte das Pesquisas em Ensino de Geografia Publicadas em Periódicos Nacionais: perspectivas e tendências
}

\author{
A Literature Review of the Research Published About on Teaching Geography Published in \\ National Journals: perspectives and trends
}

\author{
Ricardo Lopes Fonseca \\ Doutorado em Geografia, Universidade Estadual de Londrina, Brasil \\ ricardolopesf@uel.br
}

\begin{abstract}
Resumo
Neste artigo é apresentado o Estado da Arte das pesquisas em ensino de Geografia a partir da análise dos artigos publicados em periódicos nacionais, considerando toda a série histórica disponível de forma on line até o ano de 2016. O objetivo é investigar, a partir das publicações de artigos em periódicos nacionais on line, toda a série histórica destas publicações, possibilitando inferir acerca das perspectivas e das tendências das pesquisas no ensino de Geografia. As tabelas, gráficos e mapas estão inseridos para proporcionar ao leitor uma noção dos temas das pesquisas produzidas e sua espacialização no território nacional. Encontraram-se 1.458 artigos nesta temática, em 187 periódicos avaliados na área de Geografia, considerando-se o Qualis Periódicos quadriênio 2013-2016. Os resultados estão discutidos em dois momentos, o primeiro como um perfil quantitativo e o segundo a partir do tratamento qualitativo, por meio do método de Análise de Conteúdo, de Bardin (1977; 2011). Destacam-se categorias: políticas educacionais, processos de ensino e de aprendizagem, conteúdos da Geografia, ciência geográfica, formação de professores e sujeitos da educação. Por fim, por ser atividade árdua e complexa, o Estado da Arte desenvolve uma ação bastante difícil, especialmente em razão de sua retidão criteriosa e reflexiva, facilitando sempre o crescimento de estudos inovadores, visando ao aprimoramento dos conhecimentos do cidadão.
\end{abstract}

Palavras-chave: Ensino de Geografia; Pesquisa; Estado da Arte; Análise de Conteúdo; Perspectivas e Tendências.

\begin{abstract}
This paper presents a literature review about on teaching Geography from the analysis of articles published in national journals, considering the entire historical series until 2016, that is available online. The objective is to investigate, from the publication of articles in national journals online, the entire historical series, allowing to infer about the perspectives and trends of research on teaching Geography. The tables, graphs and maps were included to inform the subjects research and the spatial distribution in the national territory. We found 1,458 articles on this theme in 187 journals evaluated in the Geography area, considering the Qualis Periodicals quadrennium 20132016. The results were discussed in two moments, the first from a quantitative profile and the second as a qualitative treatment, using Bardin's Content Analysis method (1977; 2011). The themes are educational policies, teaching and learning processes, geography content, geographical science, training and education subjects. Research on the State of the Art has critical and reflective character that assist in the development of new research demands, concepts and paradigms. That is what we tried to achieve with this research.
\end{abstract}

Keywords: Teaching Geograph; Search; Literature Review; Content Analysis; Perspectives and Trends. 


\section{INTRODUÇÃO}

Pesquisas versando acerca do ensino de Geografia, nas últimas décadas, têm conquistado espaço nos cursos de licenciaturas desta ciência, bem como em programas de pósgraduações lato sensu e stricto sensu. Em relação à licenciatura, tem-se observado um avanço em termos de grade curricular, passando as disciplinas de cunho pedagógico a ocuparem maior carga horária, em média dois anos.

A criação e a construção do saber geográfico na escola têm como foco prioritário a formação do estudante, inserido num contexto historicamente estabelecido ao qual vive e vivencia a condição de crescimento contínuo no cerne das conexões sociais, de trabalho e de cultura.

Tendo por base o aporte epistemológico, este estudo pode ser equiparado ao que Callai, em 2010, denomina de "educação geográfica", pela qual a apreensão de informações, assim como o crescimento do saber visando à aquisição da aprendizagem agregam mecanismos importantemente necessários para a apreciação do espaço geográfico, originando uma prática de estudo e de consideração teórico-metodológica dos temas voltados à ordenação socioespacial, começando pela atividade do próprio ser humano em meio à natureza.

Em seu estudo de 2012, Cavalcanti menciona a criação de novas ações investigativas envolvendo o ensino geográfico, já que o mesmo tem apresentado contínuo progresso, o que facilita o estabelecimento de metas e de parâmetros para o ensino geográfico.

Freire, em estudo divulgado em 2002 (p. 34), explica que o ensino de Geografia desenvolvido na educação básica se mostra vinculado à ação crítica, buscando "descobrir-se em uma totalidade". A não incidência de metodologias e de fontes didático-pedagógicas, a escassez visível na preparação, seja ela inicial e/ou continuada do professor de Geografia, aliada à ineficiência presente nos tópicos curriculares corroboram para que ocorra um certo desprezo em relação à Geografia escolar, que acaba não priorizando a formação do tão propalado cidadão crítico.

Opinando acerca da produção desse conhecimento, Pinheiro (2005) argumenta que muitas investigações a respeito do ensino geográfico resultam de estudos desenvolvidos por meio de programas de pós-graduação, sendo as mesmas subsídios direcionadores à confecção de artigos científicos publicados em periódicos e em eventos, por exemplo.

Callai (2010) lembra que em meio a muitos desafios e barreiras que surgem nas pesquisas voltadas ao ensino de Geografia é possível apontar alguns mais incidentes e significativos, como: o lugar enquanto referência na abordagem das temáticas interpeladas pela Geografia; o assunto envolvendo a questão da escala global-local com referência aos episódios geográficos na Geografia escolar; a formação geográfica, no papel de intermediadora do conceito espacial; o crescimento da capacidade de leitura e levantamento cartográfico; o melhoramento da 
habilidade na aplicação de diferentes linguagens na análise geográfica; estudo efetivamente crítico acerca dos tópicos inseridos na Geografia física; adoção de concepções relacionadas ao assunto ambiental e social e, ainda, o favorecimento à verdadeira formação cidadã.

Fundamentados no caráter bibliográfico pelo qual são distinguidos, os estudos conhecidos como "Estado da Arte" (EAr), geralmente, são reconhecidos por um ideal comum: mapear e reconhecer a produção acadêmica em meio aos mais diferentes espaços do conhecimento.

Neste sentido, justifica-se a realização deste EAr pela notoriedade em realizar um método cujas características se mostrem como algo criativo e minucioso em relação à produção acadêmica e científica acerca da temática de ensino de Geografia “[...] à luz de categorias e facetas que se caracterizam enquanto tais em cada trabalho e no conjunto deles, sob os quais o fenômeno passa a ser analisado" (FERREIRA, 2002, p. 258).

O recorte temporal adotado para esta pesquisa se estende por toda a série histórica, disponível de forma on line, da produção de artigos científicos em ensino de Geografia, que inicia em 1957 e se estende até o ano de 2016, uma vez a busca por esses artigos se iniciou no primeiro semestre de 2017.

O objetivo geral consiste em investigar, a partir das publicações de artigos em periódicos nacionais on line, toda a série histórica destas publicações, possibilitando inferir acerca das perspectivas e das tendências das pesquisas no ensino de Geografia.

A problemática que norteia este trabalho visa a responder a seguinte questão: “Com base nos artigos de ensino de Geografia publicados em periódicos nacionais, disponíveis de forma on line, quais as perspectivas e as tendências das pesquisas nesta área?’”

Referente à discussão dos resultados, os mesmos se dividem em dois momentos distintos: 1) apresentação de resultados quantitativos, com a finalidade de esboçar um perfil das publicações na temática desta pesquisa; e, 2) discussão de resultados com caráter qualitativo, por meio do método de Análise de Conteúdo (BARDIN, 1977), de modo que seja possível realizar a categorização, as unidades de registros e a frequência relativa dos dados obtidos.

A partir da apresentação de tabelas, gráficos e mapas, o leitor poderá buscar um conhecimento relativo às questões relacionadas aos estudos desenvolvidos nas universidades, em quais periódicos foram ou estão sendo divulgados os conteúdos próprios do ensino de Geografia.

Sendo assim, é possível afirmar que o leitor dotado de interesse por esta matéria e que de maneira efetiva ambiciona lidar com os assuntos que envolvem o ensino geográfico poderá, por intermédio deste estudo ter conhecimento acerca das temáticas, abordagens e direcionamentos de pesquisa desta área, bem como utilizá-la como sustentação e apoio às suas próprias pesquisas. 
As ações que envolveram esse levantamento facilitam a abertura do debate a respeito do tema pesquisado, objetivando responder, de forma correspondente ao pensamento de Ferreira (2002, p. 258):

[...] que aspectos e dimensões vêm sendo destacados e privilegiados em diferentes épocas, e lugares, de que formas e em que condições têm sido produzidas certas dissertações de mestrado, teses de doutorado, publicações em periódicos e comunicações em anais de congresso e de seminários.

Entende-se assim, que o EAr desenvolve uma ação considerada enigmática, especialmente de razão de sua natureza crítica e reflexiva, buscando sempre a aprimoração e o desenvolvimento de demandas inéditas de pesquisas, conhecimentos e padrões.

Haddad (2002, p. 09) reconhece a grandeza que representa o EAr, argumentando que seus estudos

[...] permitem, num recorte temporal definido, sistematizar um determinado campo de conhecimento, reconhecer os principais resultados da investigação, identificar temáticas e abordagens dominantes e emergentes, bem como lacunas e campos inexplorados abertos a pesquisas futuras.

Um dos principais focos desse tipo de pesquisa está na busca do conhecimento que existe a respeito de algum assunto, começando, muitas vezes por um recorte temporal específico, além de sua composição e apreciação referente ao enunciado, que além da possibilidade de resgate, adéqua a produção acadêmica num campo realmente apropriado.

Sendo assim, é importante reforçar que este estudo possui um cunho bibliográfico, persistindo uma sistematização em relação à forma e às necessidades da produção acadêmica, especialmente em relação aos artigos divulgados em periódicos. Entende-se assim, que o EAr representa um estudo bibliográfico, sistemático, analítico e, especialmente, fonte de crítica voltada à produção acadêmica.

As pesquisas dessa natureza costumam estar fundamentadas nas leituras dos resumos, no entanto, Barreto e Pinto (2001, p. 5 e 6) exprimem, nestes termos, sobre a importância que representa este modelo de pesquisa:

Com os avanços da informática, a seleção de fontes tem podido contar com os bancos de dados existentes, cuja sistematização regular de informação possibilita maior abrangência do levantamento, se, de um lado, eles ampliam o universo contemplado, de outro, armazenam os dados de forma resumida, o que deve ser levado em conta ao se utilizar tais fontes, pois nem sempre os resumos disponibilizam as informações básicas necessárias para a análise. O ideal, nesses casos, seria o exame dos textos originais, ainda que se admita a dificuldade de acesso a eles. Quando não se dispõe de bancos de dados, o próprio processo de elaboração dos estados do conhecimento tem levado à organização desses bancos. 
Faz-se importante destacar que o pesquisador precisa manter a atenção ao se valer de textos sintetizados como fontes para definir os parâmetros, já que essa ação pode implicar na falta da conciliação necessária para a reprodução da análise do EAr, ou seja, existe a possibilidade de o pesquisador abordar resumos extremamente insuficientes. Assim, é importante que o pesquisador consiga assim se valer de outras fontes para demonstrar sua capacidade criativa, superando o desafio e indo além do resumo da obra estudada.

Desta forma, o acúmulo de informações referentes a um campo específico que tem apresentado um crescimento acentuado tem exposto a obrigação de repassá-lo para o público em geral, o que confirma a importância que representa o EAr na construção das pesquisas.

Por fim, este artigo apresenta nas seções seguintes seus procedimentos metodológicos, resultados e considerações finais.

\title{
2. PROCEDIMENTOS METODOLÓGICOS
}

Os procedimentos metodológicos adotados para esta pesquisa estão divididos em duas etapas, a primeira aborda o método de análise de resultados qualitativos e a segunda descreve o processo de coleta dos dados que serão analisados na sequência.

\section{a. Do método de análise dos resultados}

Algumas ações criteriosas e importantemente necessárias a um estudo qualitativo estão expressas por Salvi (2009, p. 175-176), sendo elas:

\begin{abstract}
A primeira regra de categorização é baseada no preceito de que categorias necessitam ser válidas, pertinentes ou adequadas aos objetivos da análise, à natureza do material que está sendo estudado e às questões a que se pretende responder com a pesquisa. [...]. A segunda regra básica é a da exaustividade. As categorizações deverão ser exaustivas no sentido de poderem enquadrar todo o conteúdo. [...]. A terceira regra geral da categorização é a da homogeneidade, ou seja, a sua organização deve ser fundamentada em um único princípio ou critério de classificação. [...] significa poder afirmar que todo o conjunto é estruturado em uma única dimensão de análise, numa única variável. [...]. A quarta regra da categorização é a da exclusão mútua. O pesquisador precisa assegurar que cada elemento possa ser classificado exclusivamente em apenas uma categoria. [...]. A quinta regra da categorização é a da objetividade, consistência ou fidedignidade, estreitamente relacionada ao critério de exclusividade. [...].
\end{abstract}

Faz-se possível perceber, contudo, que a classificação dos dados aponta para um dispositivo de análise pelo qual se busca um encaminhamento para as informações auferidas.

Deste modo, é importante destacar a argumentação exposta por Laville e Dionne (1999) defendendo a importância que representa um bom conjunto de categorias se mostrar especialmente adequado, sendo tão exigível quanto possível, dispensando formações exacerbadas, mas precisas e exclusivas. 
Categorização final das unidades de análise: Essa distinção remete a uma apreciação das temáticas e da classificação de sua categorização.

O processo requer uma consistência efetiva dos recortes sustentada em regras que só são aprovadas após debatidas, sendo consideradas uma a uma as unidades, sob critérios rigorosos de análise, visando à escolha da categoria ideal para cada uma (LAVILLE; DIONNE, 1999). Vale lembrar ainda que o pesquisador precisa ter conhecimento da realidade estudada, assim como demonstrar competência para identificar as modulações nas quais estão expressas as argumentações, seja por meio de palavras, falhas opostas, interrupções ou mesmo repetições, e até mesmo na própria ideia manifestada nessas oportunidades. É importante constatar que os pesquisadores da ciência geográfica têm se aproveitado dessa ferramenta e aperfeiçoado o conhecimento científico da área.

A organização dos dados: Nesta subdivisão são apresentadas as fases que comprovaram a apreciação dos resultados por meio, neste caso, da técnica de Análise de Conteúdo (AC), de Bardin (1977; 2011), iniciada com a reunião das informações, seguida pela categorização e unidades de registro e o processo de desenvolvimento do metatexto. É importante expor a maneira como os dados foram ordenados obedecendo a essa organização sequencial:

Primeira Fase: O fundamento de um estudo se dá com a organização dos documentos a serem apreciados; nesta pesquisa os documentos são os artigos científicos com a temática voltada para o ensino de Geografia. Para a efetiva realização dessa ação, é necessariamente importante considerar todas as possibilidades existentes, isto é, permite-se o esgotamento de toda a capacidade de comunicação, não se admitindo, contudo, uma só ação omissa que seja; representatividade (a parte selecionada deve representar a totalidade); homogeneidade (os dados representativos precisam ser correspondentes ao mesmo tema, construídos com base em ações idênticas e conseguidas por pessoas semelhantes); pertinência (os dados anotados devem necessariamente estar em conformidade com a temática e a finalidade do estudo proposto) e exclusividade; reforçando que um elemento não deve ser incluso em mais de uma categoria.

Segunda Fase: Esta fase é considerada como sendo a fase de exploração do material e nela são estabelecidas as Unidades de Registro (UR) das categorias acompanhadas de suas respectivas conceituações.

Em estudo desenvolvido em 2011, Bardin esclarece que das categorias são exigidas algumas qualificações, sendo as mesmas:

- Exclusão mútua: cada componente só pode preencher uma categoria;

- Homogeneidade: para o reconhecimento de uma categoria só é permitida uma grandeza na análise. Havendo a persistência de níveis distintos de análise, pode-se entender que os mesmos devam ser distribuídos em categorias também distintas; 
- Pertinência: as categorias não podem se contrapor às objetividades do investigador, assim como às finalidades do estudo, às questões orientadoras e às particularidades da mensagem.

- Objetividade e fidelidade: se as categorias se mostrarem ordenadamente dispostas e os argumentos e indicadores que validam a inclusão de um elemento numa determinada categoria se apresentarem límpidos, logicamente não serão observadas discrepâncias naquilo que se refere à subjetividade por parte dos analistas;

- Produtividade: as categorias serão consideradas produtivas quando os resultados forem gratificantes e definitivos em relação às novas possibilidades, e às informações exatas.

Entendendo que as Unidades de Registro (UR) estão sujeitas a diversas mudanças e situações e a respeito delas alguns pesquisadores acrescentarão expressões, outros poderão demonstrar aptidão pelas sentenças, parágrafos ou mesmo pela composição inteira, a prática aplicada na abordagem de tais UR poderá ser demonstrada de formas variáveis. É possível perceber ainda que enquanto uns preferem realizar associações de palavras ou de expressões, outros preferem se aprofundar na construção da investigação sobre a fundamentação lógica da transcrição ou de seus fragmentos, havendo ainda aqueles que priorizam preservar a atenção na direção de questões anteriormente estabelecidas (BARDIN, 2011).

Terceira Fase: Reconhecida como sendo a etapa do desenvolvimento da AC, essa representa o tratamento dos resultados, ou seja, a interpretação e apreciação dos resultados. Com fundamento nos resultados brutos, o pesquisador os transforma em consistentes e significativos.

Esse entendimento consegue suplantar a proposição contida nos documentos, já que pode favorecer a matéria oculta, isto é, o conhecimento claro exposto por trás do aprendizado recente. A realidade presente na $\mathrm{AC}$ pode ser sustentada em vários tópicos de observação, representados pelos pontos de atração da comunicação. Essa percepção representa, dessa forma, um dispositivo de referência para que sejam reconhecidas as causas - variáveis inferidas - a começar pelos efeitos - variáveis de interferência ou indicadores, referências - de conformidade como aponta Bardin (2011).

Durante a realização interpretativa das informações é importante preservar a atenção nos sinalizadores teóricos reunidos à investigação, já que os mesmos propiciam segurança, além das chances necessárias ao estudo a ser reproduzido. A conexão que reúne os dados angariados e a fundamentação teórica certamente darão a importância devida à interpretação.

De acordo com o pensamento de Bardin (1977, p. 135): 
C'est l'unité de signification à coder. Elle correspond au segment de contenu à considérer comme unité de base em vue de La catégorisation et Du comptage fréquentiel. L'unité d'enregistrement peut être de nature et de taille três variables. Une certaine ambiguïté règne quant aux critères de distinction des unités d'enregistrement. ${ }^{1}$

As intuições que remetem às afirmações deverão estar sempre voltadas à busca daquilo que se acha inexplorado sob a provável realidade, condição que representa a argumentação expressa, demonstrando de maneira mais consistente algumas afirmações tidas como incompletas.

Ao término dessa fase foi possível idealizar e confeccionar o metatexto. Com o desenvolvimento desse novo ingrediente foi possível dar início a uma série de explanações e apreciações nas quais não se admitem argumentações imprecisas nas conexões difundidas entre as categorias e suas UR. Entende-se assim que o metatexto agrega a percepção do pesquisador acerca dos significados e significantes perceptíveis em cada categoria e UR.

O metatexto representa uma técnica apresentada pelo pesquisador Roque Moraes, em seu estudo de 2003, se propondo a analisar a argumentação contida nos objetos/instrumentos. Por essa acepção, esta prática facilita o desenvolvimento qualitativo do tratamento dos resultados juntamente com a $\mathrm{AC}$, defendida por Bardin.

Conforme explicação de Moraes (2003, p. 202), o metatexto “[...] constitui um conjunto de argumentos descritivo-interpretativos capaz de expressar a compreensão atingida pelo pesquisador em relação ao fenômeno pesquisado, sempre a partir do corpus de análise".

Deste modo, é interessante destacar também que a classificação relativa às informações inclusas no metatexto não depende apenas da validade e confiabilidade da análise reproduzida, mas, principalmente, da prática assumida pelo pesquisador como verdadeiro autor de suas interpretações. Sendo assim, é possível afirmar que a apreciação presente neste estudo está direcionada à produção do referido metatexto.

No quadro 1, expõe-se o modelo adotado por este pesquisador para a apresentação dos resultados qualitativos.

Quadro 1 - Modelo de categorização.

\begin{tabular}{|c|c|c|}
\hline CATEGORIA "no." & TÍTULO DA CATEGORIA \\
\hline Descrição da Categoria. & $\begin{array}{c}\text { DESCRIÇÃO DAS UNIDADES } \\
\text { DE REGISTROS }\end{array}$ & $\begin{array}{c}\text { FREQUÊNCIA } \\
\text { RELATIVA }\end{array}$ \\
\hline UNIDADES DE REGISTROS & $\begin{array}{c}\text { Palavras relacionadas à unidade. } \\
\text { UR1 - Título da unidade }\end{array}$ & $\mathrm{n}^{\text {o. } \%}$ \\
\hline UR2 - Título da unidade & Palavras relacionadas à unidade. & $\mathrm{n}^{\circ} . \%$ \\
\hline UR3 - Título da unidade & Palavras relacionadas à unidade. & \\
\hline & METATEXTO \\
\hline
\end{tabular}

Org.: o próprio autor.

1 “É a unidade de significação a ser codificada. Corresponde ao conteúdo considerado como unidade básica para a categorização e contagem frequencial. A unidade de registro pode ser de natureza e dimensão muito variáveis. Certa ambiguidade rege os critérios de distinção de unidades de registro". (Tradução nossa). 
A aplicação da $\mathrm{AC}$ enquanto método da pesquisa qualitativa, pode ser considerada como importante técnica para uma análise consistente de resultados, já que sua utilização facilitou para o reconhecimento de alguns pressupostos teóricos e metodológicos dos processos que envolvem o ensino e a aprendizagem, por intermédio de suas categorias e UR, assim como avaliar um determinado espaço do saber.

\section{b. Da coleta dos dados}

Os procedimentos que levaram aos resultados obtidos seguiram algumas fases, a seguir:

$1^{a}$ fase: no site da Coordenação de Aperfeiçoamento de Pessoal de Nível Superior (CAPES), por meio do banco de dados do Qualis Periódicos ${ }^{2}$, foram realizadas algumas seleções de itens para filtrar a busca por uma lista de periódicos a serem considerados para a coleta dos dados, tais como: a) Evento de Classificação - quadriênio 2013-2016 e b) Área de Avaliação - Geografia. Desta busca foi gerado pelo próprio sistema da CAPES um arquivo com a listagem completa de todos os periódicos aplicados a estes dois parâmetros de buscas. Essa fase foi realizada no dia 26 de janeiro de $2017^{3}$;

$\mathbf{2}^{\mathbf{a}}$ fase: foram considerados apenas periódicos nacionais e que tivessem uma versão on line, neste sentido, aqueles que apareceram em duplicidade ou que possuíssem apenas a versão impressa foram descartados. Deste modo, chegou-se ao número total de 801 periódicos;

$\mathbf{3}^{\text {a }}$ fase: ao longo de todo o ano de 2017 foram realizadas buscas de artigos com temáticas na área de ensino de Geografia. Para essa coleta foram considerados todas as edições que estivessem disponíveis nas plataformas on line destes periódicos até o ano de 2016, de modo que fosse possível padronizar a busca por esses trabalhos. As estatísticas a este respeito estão apresentadas na seção dos resultados deste manuscrito;

$4^{\text {a }}$ fase: no decorrer de todo o ano de 2018 foram classificados todos os artigos que tratavam de ensino de Geografia, conforme estrutura do quadro 2. periódico. 
Quadro 2 - Modelo para classificação dos artigos de ensino de Geografia.

\begin{tabular}{|l|c|}
\hline \multicolumn{2}{|c|}{ Código do arquivo: } \\
\hline Título & \\
\hline Autoria & \\
\hline Instituição do $(\mathrm{a} / \mathrm{s})$ autor $(\mathrm{a} / \mathrm{s})$ & \\
\hline Formação dos $(\mathrm{a} / \mathrm{s})$ autores $(\mathrm{a} / \mathrm{s})$ & \\
\hline Titulação dos $(\mathrm{a} / \mathrm{s})$ autores $(\mathrm{a} / \mathrm{s})$ & \\
\hline Ano da publicação & \\
\hline Revista & EIXOS \\
\hline Referências (ABNT) & \\
\hline \multicolumn{2}{|c|}{ GERAL } \\
\hline Temática & Org.: o próprio autor. \\
\hline \multicolumn{2}{|c|}{}
\end{tabular}

$5^{\text {a }}$ fase: no decorrer do ano de 2019 foi realizado o processo de categorização dos resultados, com base nos pressupostos da AC. Para a realização desta fase, este pesquisador selecionou as categorias e as UR de acordo com as informações mencionadas nos resumos de cada artigo; salvo algumas situações específicas foram necessárias leituras de todo o artigo, fosse pela falta de um resumo, fosse pela falta de clareza nas informações presentes neles. Desta forma, os dados foram classificados em categorias e UR, e, na sequência, realizado o metatexto.

Ao todo, foi possível estabelecer cinco categorias a priori (categorias que este pesquisador havia estabelecido no início desta fase, com base na classificação encontrada na $4^{\mathrm{a}}$ fase) e uma emergente (a partir dos artigos que não foram inseridos em nenhuma categoria a priori); cada categoria possui suas especificidades, portanto, suas UR serão distintas entre si, são elas entre os parênteses estão as UR -: 1) políticas educacionais (modalidades de educação, educação ambiental, currículo, livro didático, e educação não-formal), 2) processos de ensino e de aprendizagem (recursos didáticos-pedagógicos, tecnologias digitais de informação e de comunicação (TDIC), trabalho de campo, didática, avaliação, teorias de aprendizagem, e psicologia da educação), 3) conteúdos da Geografia (cartografia, Geografia humana, Geografia física, e inter/multi/trans disciplinaridade), 4) ciência geográfica (história e correntes do pensamento geográfico, categorias de análise do espaço geográfico, pesquisa em ensino, e objeto de estudo da ciência geográfica - espaço geográfico), 5) formação de professores (formação inicial, saberes docentes, e formação continuada), e 6) sujeitos da educação (discentes e docentes). A ordem estabelecida para a apresentação das categorias e das respectivas UR está relacionada ao percentual de incidência, logo, da maior frequência a menor.

A seguir, os resultados organizados em três momentos: a) perfil quantitativo das publicações, b) tratamento qualitativo dos resultados, e c) considerações gerais. 


\section{RESULTADOS E DISCUSSÕES}

Os resultados estão organizados em dois momentos: perfil quantitativo e tratamento qualitativo. Na sequência, é apresentada uma consideração geral acerca desse conjunto de informações.

\section{a. Perfil quantitativo dos resultados}

Conforme mencionado nos procedimentos metodológicos, após o processo de filtragem foram obtidos o total de 801 periódicos para serem realizadas as buscas por artigos de ensino de Geografia. Ao todo, 187 revistas apresentaram ao menos a publicação de um artigo versando acerca da temática deste manuscrito.

Nem todos os periódicos que publicaram a respeito do ensino de Geografia possuem seu foco e escopo em Geografia. Pode-se observar, na figura 1, a distribuição destes periódicos de acordo com seu foco e escopo concentra a maior parte na Geografia, seguido por Outras áreas, depois Educação e Geociências.

Compõe as Outras Áreas e suas respectivas quantidades de revistas, as seguintes: Interdisciplinar com 32 periódicos, História com seis, Ciências Humanas (cinco), Multidisciplinar (dois); com apenas uma revista: Água, Arquitetura e Urbanismo, Biologia, Cartografia, Ciências Exatas, Climatologia, Educação Ambiental, Geopolítica, Informação e Comunicação, Literatura, Meio Ambiente, Paleontologia, Pedologia, Sociologia, Turismo, Urbana. Cinco periódicos não possuíam em seu site a informação de "foco e escopo".

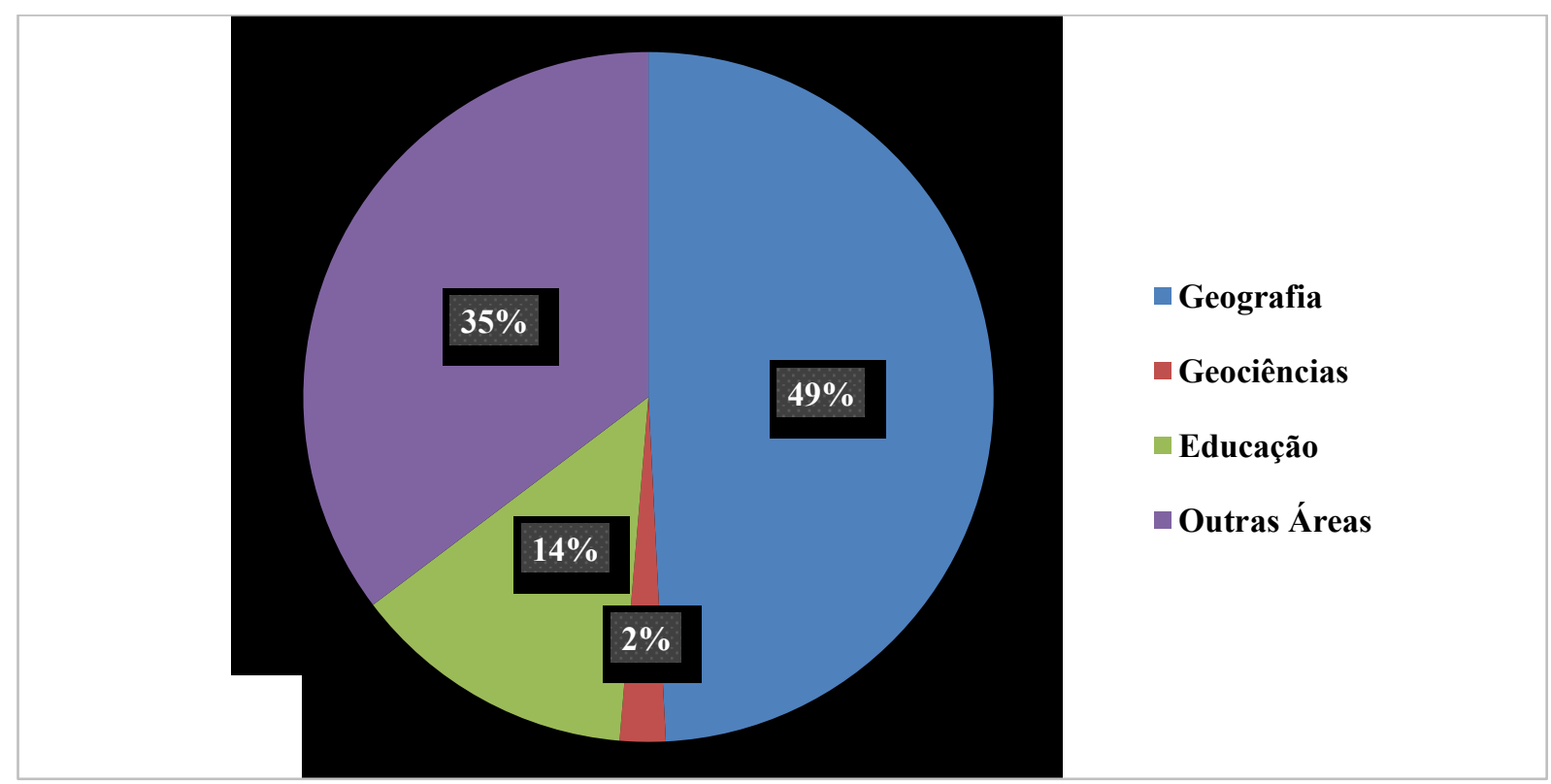

Figura 1 - Distribuição do foco e escopo dos periódicos que publicaram algum artigo de ensino de Geografia. Org.: o próprio autor. 
Após verificar 60.217 artigos científicos, foram encontrados 1.458 abordando o ensino de Geografia como temática central. A distribuição do total de artigos considerando o foco e escopo mostra que a maioria dos artigos que apresentam algum trabalho em ensino de Geografia estão concentrados em Outras Áreas, seguida por Geografia, Educação e Geociências.

Contudo, este tipo de inferência necessita de certos cuidados, pois, a proporção de artigos publicados para cada periódico está condicionada à política de cada revista, e, neste caso, corresponde ao total de uma parcela específica que foi investigada, isto é, os periódicos que estão avaliados no Qualis Periódicos na área de Geografia e que publicaram alguma pesquisa de ensino de Geografia.

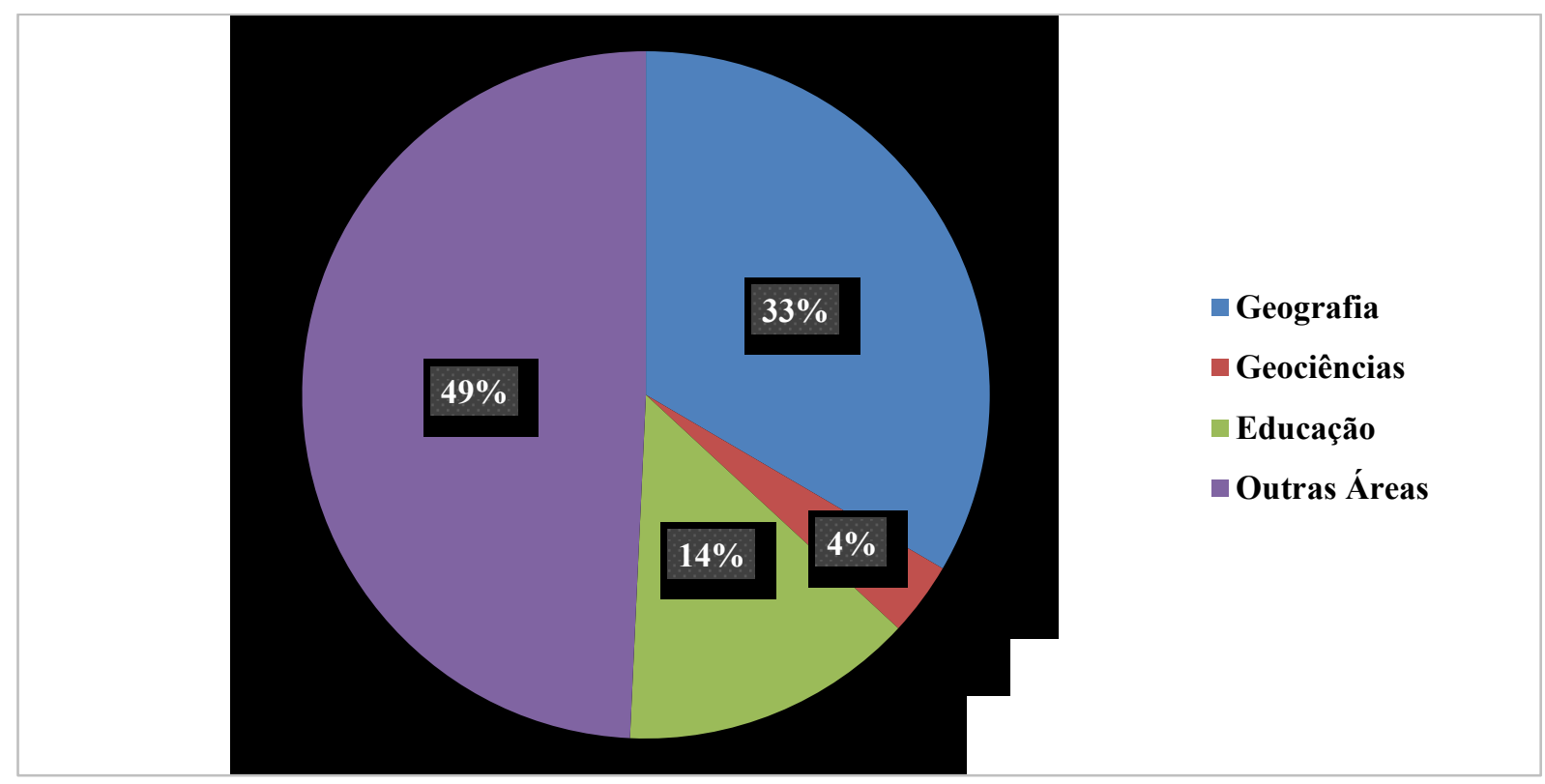

Figura 2 - Distribuição por total de artigos publicados. Org.: o próprio autor.

Ao filtrar apenas o foco e escopo em Geografia (tanto para o total de artigos nessa área, quanto os de ensino de Geografia publicados nestes), se chegará a 6,3\% do total de publicações considerando-se apenas este recorte. Contudo, este tipo de avaliação não leva em consideração o total de artigos publicados em todos os periódicos de Geografia, apenas aqueles que apresentaram a incidência de algum trabalho voltado para a temática desta pesquisa, uma vez que diversos periódicos realizam somente publicações de uma área específica da ciência geográfica.

$\mathrm{Na}$ figura 3, pode-se verificar que a distribuição de artigos em Ensino de Geografia concentra pouco mais de 1/4 nas revistas com foco e escopo em Geografia, seguida por Outras Áreas, Educação e Geociências. 


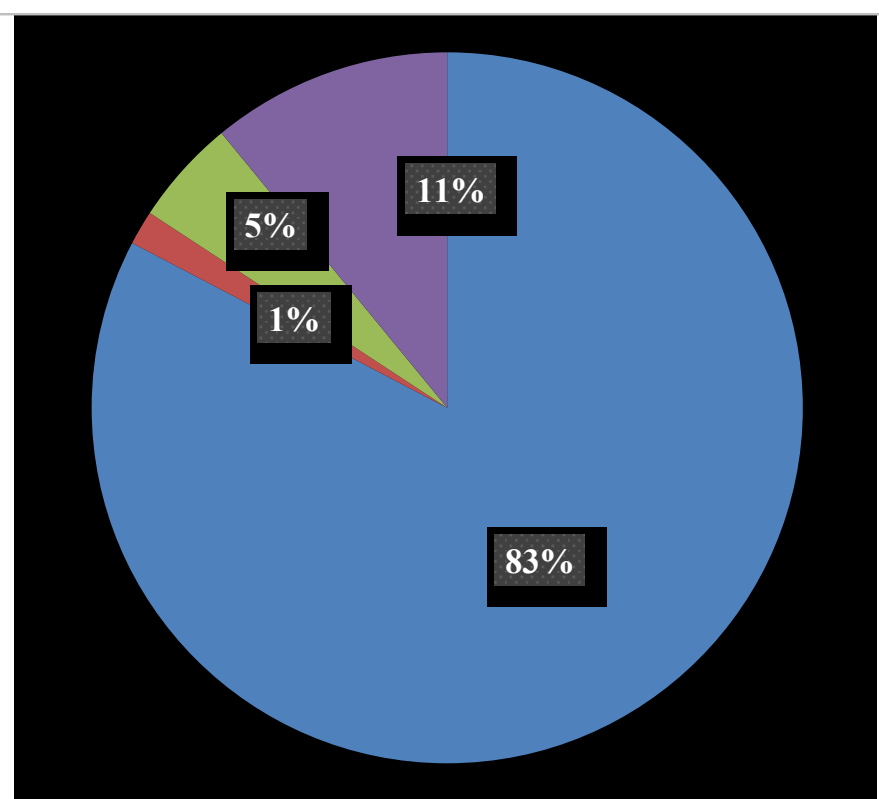

- Geografia

Geociências

Educação

- Outras Áreas

Figura 3 - Distribuição dos artigos de ensino de Geografia, por foco e escopo dos periódicos em que foram publicados. Org.: o próprio autor.

Ao tratar do Qualis Periódicos (quadriênio 2013-2016), levou-se em consideração a classificação informada para a área de Geografia. O Qualis com maior incidência de periódicos é B4 com 46, seguido de B5 (38), C (30), B3 (25), B1 (20), B2 (16), A2 (oito) e A1 (quatro), conforme figura 4. Deve-se levar em consideração o fato de que quanto mais alto o estrato menos periódicos há nesse Qualis, o que justifica uma menor quantidade de incidência nos Qualis A, em relação ao B e ao C.

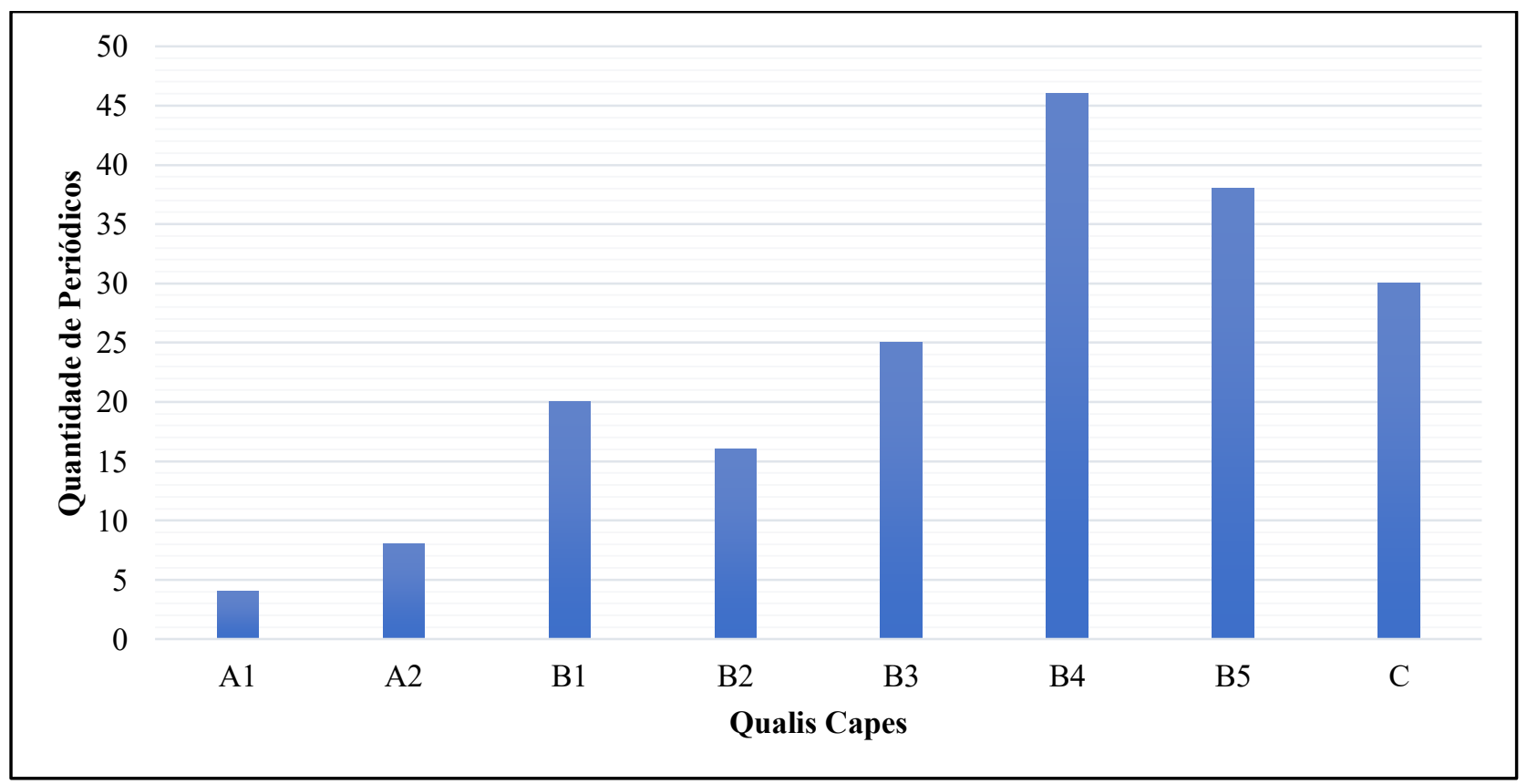

Figura 4 - Quantidade de periódicos por Qualis Periódicos.

Org.: o próprio autor. 
Quanto à distribuição dos artigos de ensino de Geografia publicados, ao se considerar o Qualis Periódicos, a origem da publicação destas pesquisas, pode-se notar, na figura 5, um equilíbrio no estrato B, variando de $15 \%$ a $18 \%$, enquanto o estrato A2 tem $7 \%$ e o A1 4\% - que se justifica pelo fato de haver menos periódicos nesta faixa de classificação.

$\mathrm{O}$ estrato $\mathrm{C}$ aparece com $6 \%$. Neste caso, inúmeros periódicos avaliados em $\mathrm{C}$ possuem poucas edições, pois, foram criados recentemente.

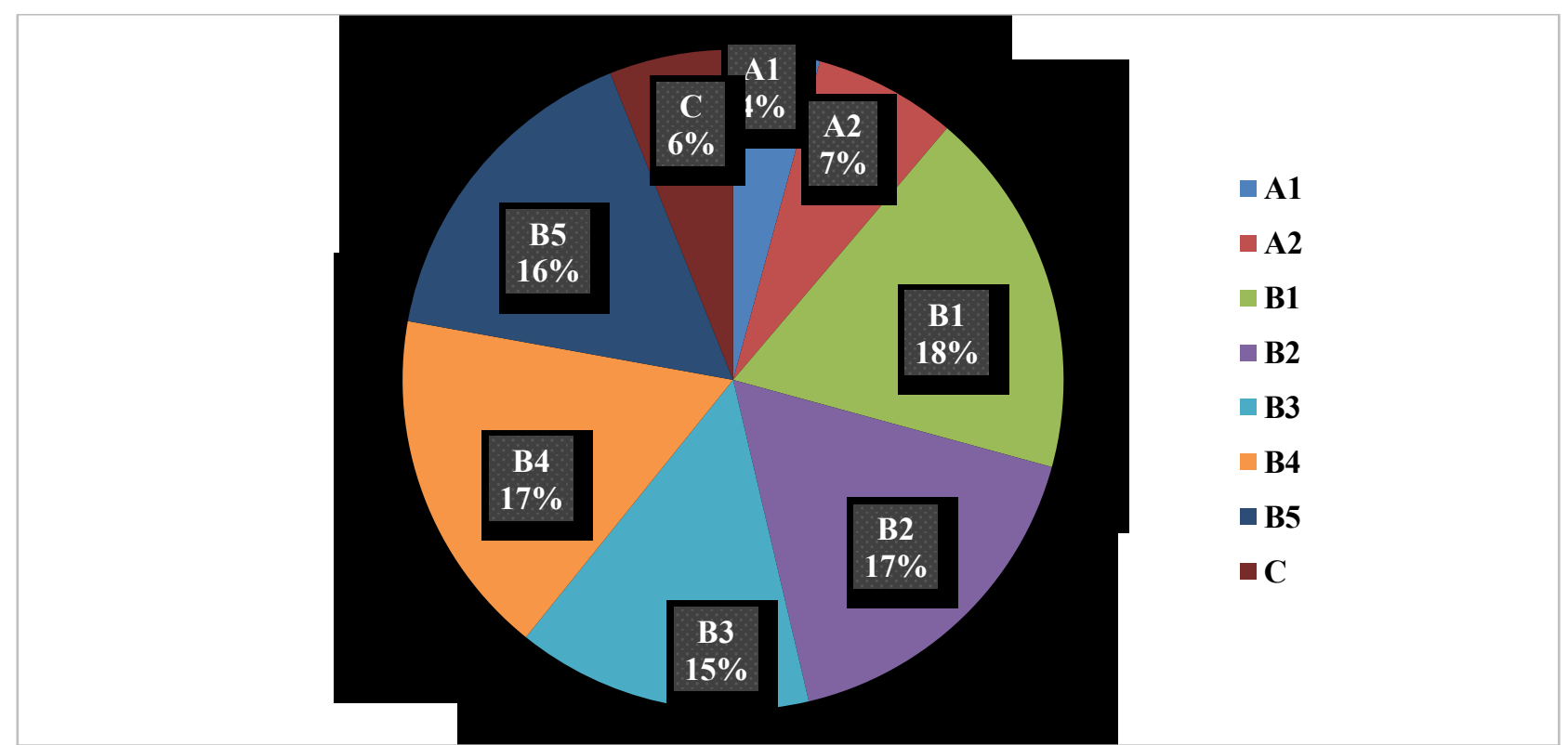

Figura 5 - Distribuição dos artigos de ensino de Geografia, conforme Qualis Periódicos dos periódicos em que foram publicados.

Org.: o próprio autor.

Ao se buscar os 10 periódicos que possui maior número de publicações de ensino de Geografia todas essas revistas possuem foco e escopo em Geografia. Além disso, os quatro periódicos com mais publicações são aqueles que estão focados para as publicações de pesquisas voltadas para o ensino de Geografia. (Quadro 3).

Quadro 3 - Ranking dos 10 periódicos com maior quantidade de publicações de artigos em ensino de Geografia

\begin{tabular}{|c|l|c|}
\hline QUALIS & \multicolumn{1}{|c|}{ PERIÓDICOS } & $\begin{array}{c}|c| \\
\text { QUANTIDADE } \\
\text { DE ARTIGOS }\end{array}$ \\
\hline B4 & REVISTA DE ENSINO DE GEOGRAFIA & 95 \\
\hline B3 & $\begin{array}{l}\text { GEOSABERES: DE } \\
\text { GEOEDUCACIONAIS }\end{array}$ & 93 \\
\hline B2 & REVISTA BRASILEIRA DE EDUCAÇÃO EM GEOGRAFIA & 84 \\
\hline B2 & GEOGRAFIA ENSINO \& PESQUISA & 67 \\
\hline B5 & BOLETIM PAULISTA DE GEOGRAFIA & 62 \\
\hline B1 & BOLETIM GAÚCHO DE GEOGRAFIA & 59 \\
\hline B1 & GEOGRAFIA (LONDRINA) & 49 \\
\hline B1 & CAMINHOS DA GEOGRAFIA (UFU. ONLINE) & 36 \\
\hline A2 & BOLETIM DE GEOGRAFIA (ONLINE) & 32 \\
\hline A1 & BOLETIM GOIANO DE GEOGRAFIA & 32 \\
\hline
\end{tabular}

Org.: o próprio autor. 
Exceto o periódico Caminhos da Geografia (UFU), que iniciou suas atividades no ano 2000, as demais revistas que aparecem na sequência são aquelas possuem uma longa trajetória de existência, com mais de 35 anos, sendo o Boletim Paulista de Geografia com publicações desde 1949.

Por meio da figura 6, pode-se observar a evolução da quantidade de periódicos com publicações em ensino de Geografia. É importante explicar que esses anos se referem ao início das atividades destas revistas, e não necessariamente que neste ano informado tenha tido alguma publicação acerca do ensino de Geografia.

O Boletim Paulista de Geografia é o periódico mais antigo entre os que tenha tido alguma publicação acerca do ensino de Geografia e que possua a versão on line, data desde 1949.

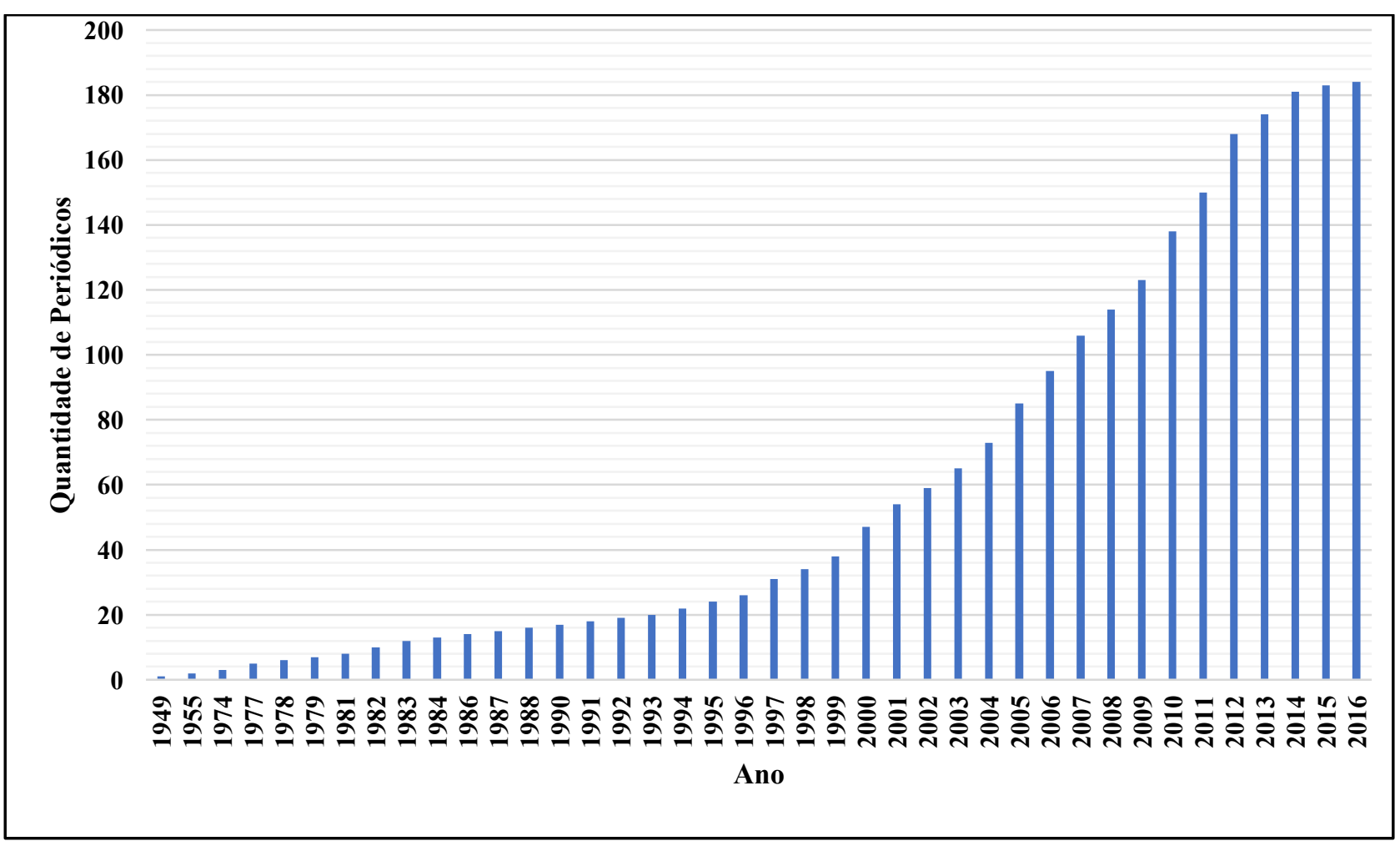

Figura 6 - Quantidade de periódicos por ano.

Org.: o próprio autor.

$\mathrm{Na}$ figura 7, é possível observar a evolução da quantidade de artigos de ensino de Geografia. Sendo a primeira incidência no ano de 1957, cujo título é "Papel e valor do ensino da geografia e de sua pesquisa", de autoria de Pierre Monbeig e publicado no Boletim Geográfico do Rio Grande do Sul.

O ano de 2014 foi o que atingiu a maior incidência numérica de publicações, com 231 publicações. Faz-se necessário informar que 34 artigos não possuem a informação/dados a respeito da publicação. 


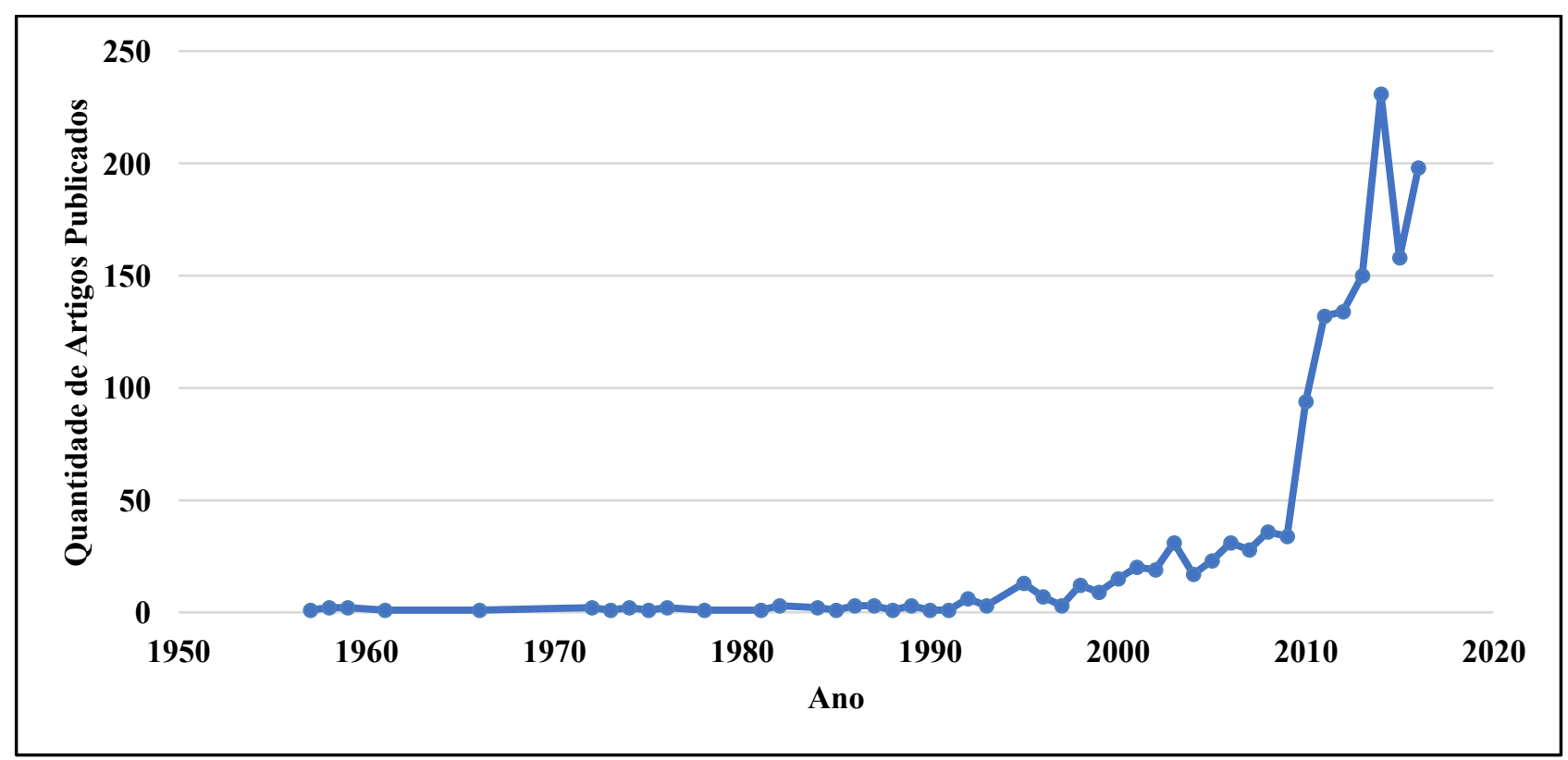

Figura 7 - Quantidade de artigos com temática em ensino de Geografia, por ano de publicação. Org.: o próprio autor.

Conforme figura $8,41 \%$ dos autores com publicação nesta temática não possuíam a titulação informada no artigo. Ao se considerar apenas aqueles que mostravam alguma titulação no artigo: 49\% com doutorado, seguido de 24\% com mestrado, 21\% graduação, 5\% especialização, $1,3 \%$ pós-doutorado e $0,7 \%$ livre docência.

Ao todo, foram 2.645 autores envolvidos nas publicações, destes 2.395 são brasileiros, 129 são de outras nacionalidades e 121 não mostraram essa informação. É válido mencionar, que na formatação dos artigos nem todos os periódicos pedem para colocar a titulação.

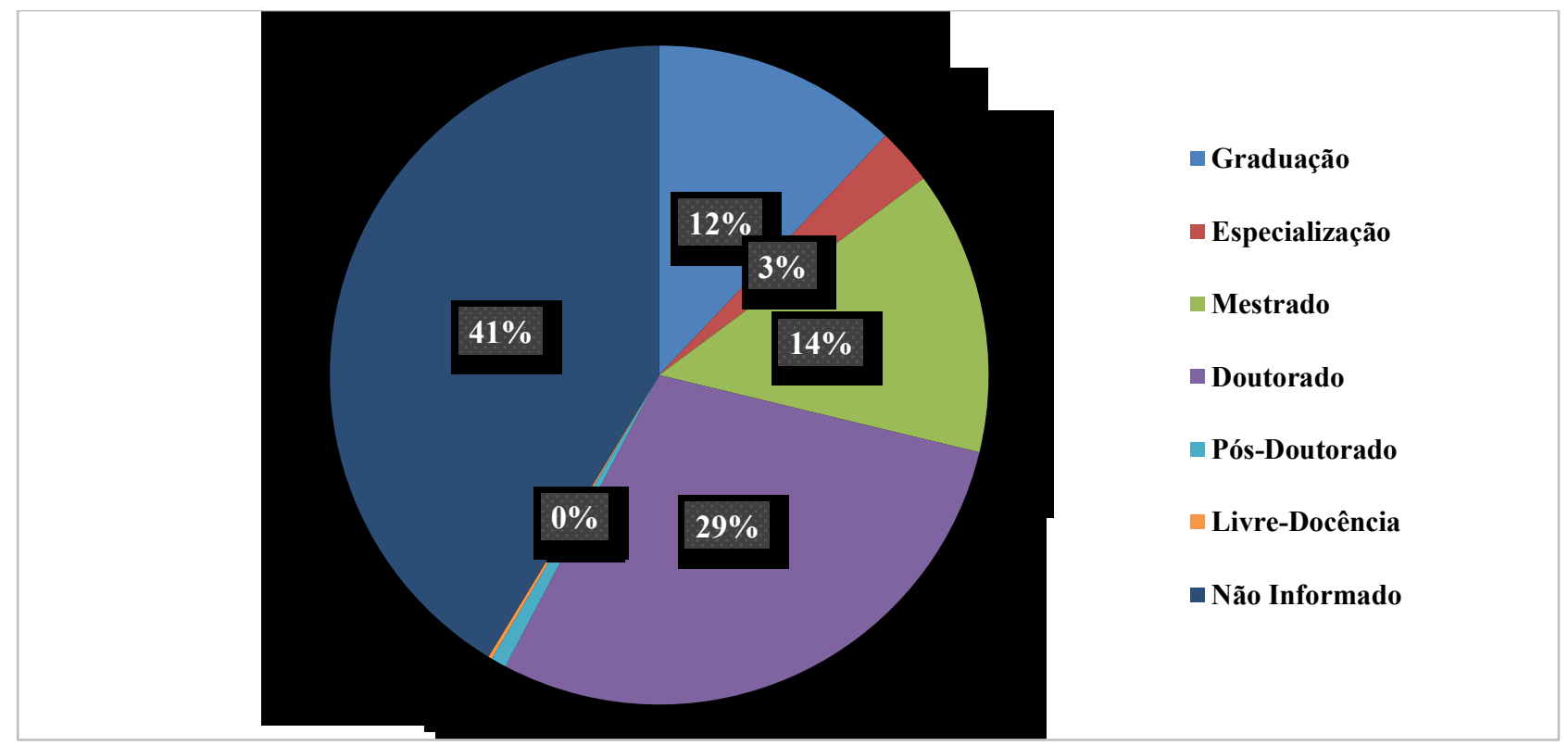

Figura 8 - Titulação informada na publicação.

Org.: o próprio autor. 
A figura 9 mostra a distribuição destes autores no território brasileiro, por vínculo informado no artigo publicado. Sendo que São Paulo é a unidade federativa com maior quantidade de incidência destes autores, com 431, seguido de PR (340), MG (292), RS (267) e RJ (140). Amapá é o que possui menos, com apenas um, AC (dois), RR (quatro), RO (nove) e ES (12).

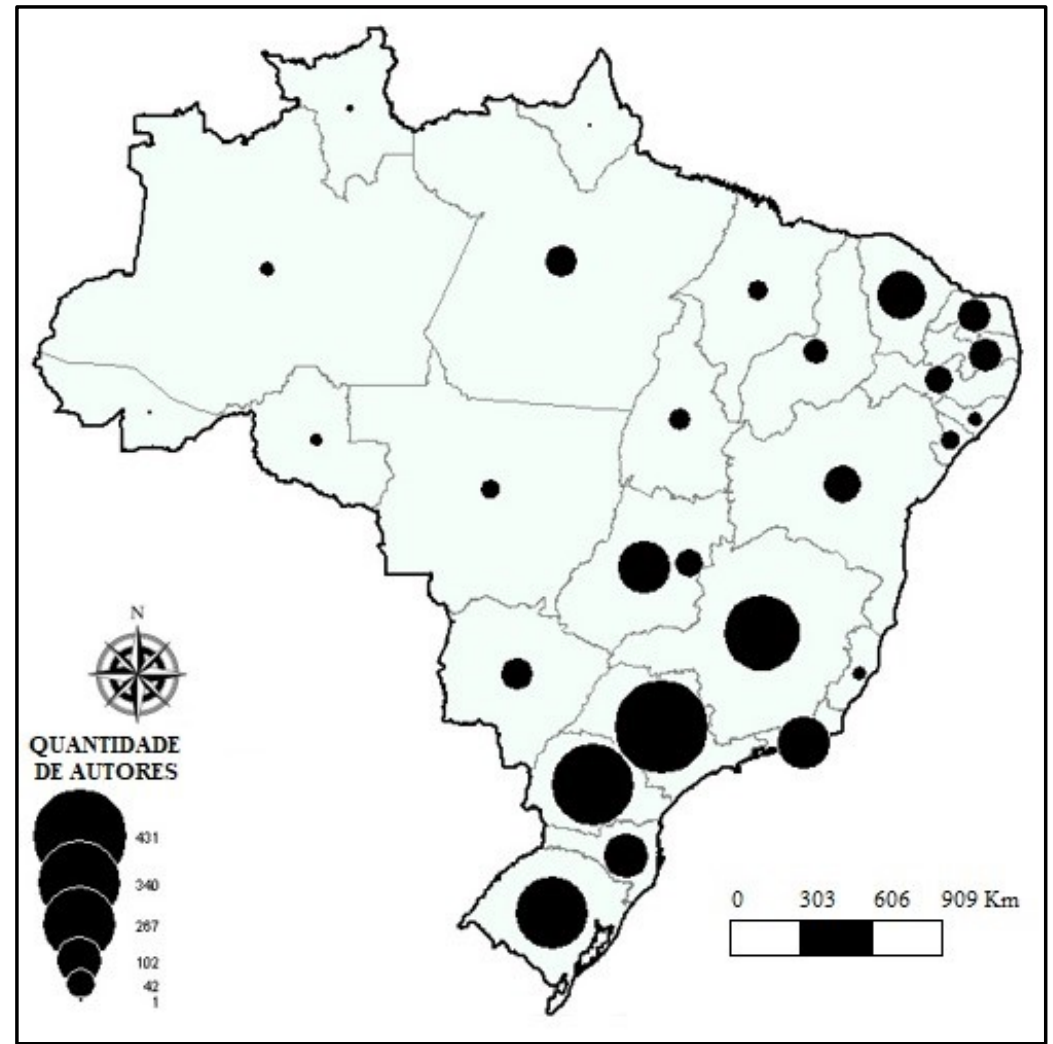

Figura 9 - Distribuição de autores, por Unidade Federativa. Org.: o próprio autor.

Entre os países com maior número de autores Portugal aparece em primeiro com 28, seguido por Argentina (19), Espanha (18) e Colômbia (15). (Figura 10)

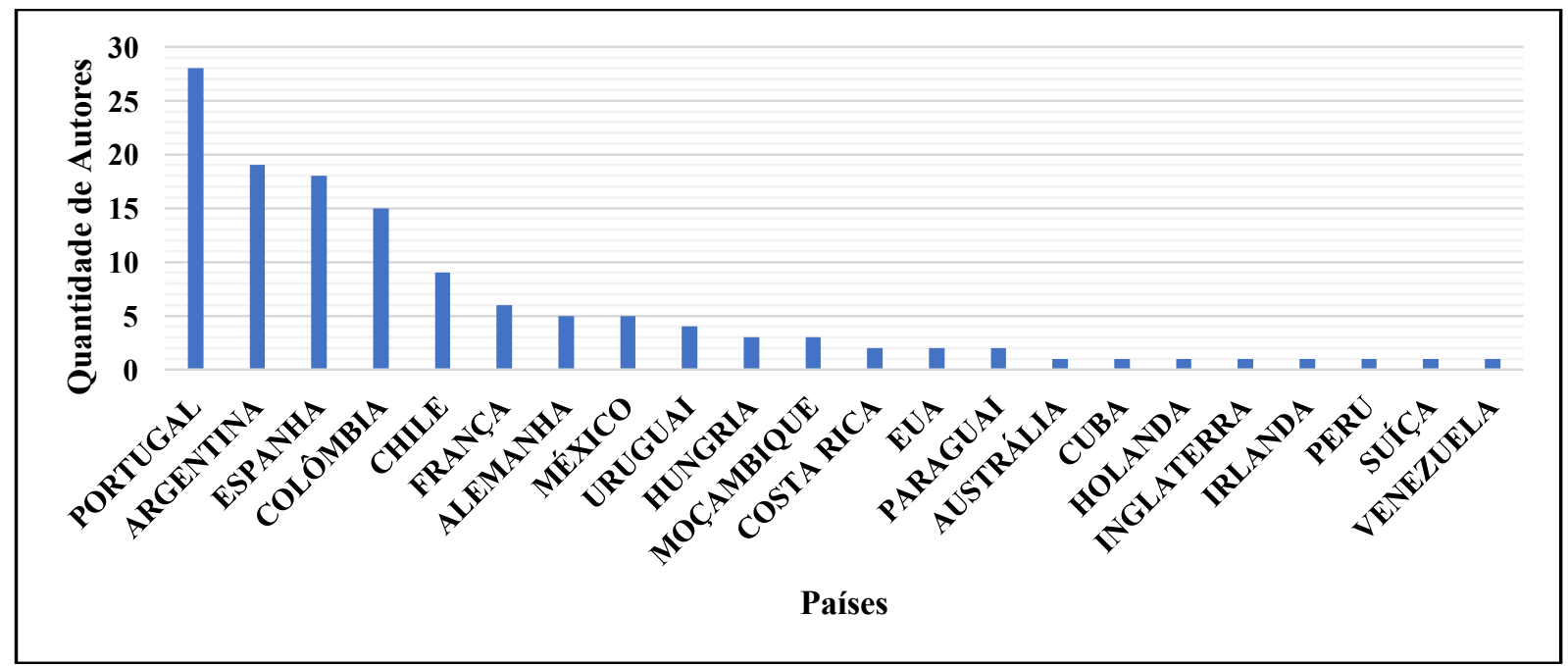

Figura 10 - Nacionalidade estrangeira dos autores. Org.: o próprio autor. 
A figura 11 evidencia o vínculo institucional dos periódicos que publicaram algum artigo em ensino de Geografia. Cabe destaque ao estado do Acre que não contou com qualquer publicação. A maior concentração está no estado de São Paulo, seguido de Minas Gerais, Paraná e Rio de Janeiro.

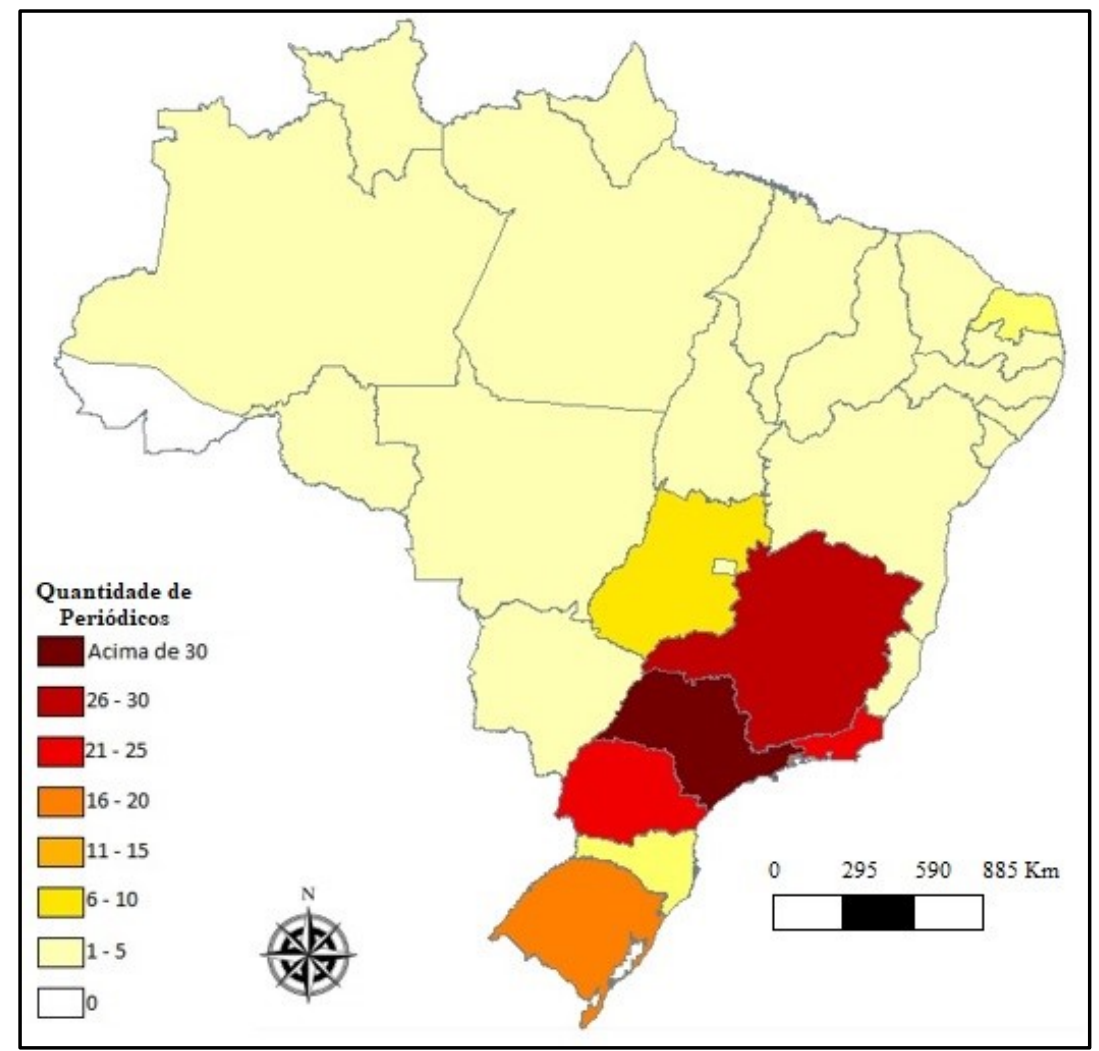

Figura 11 - Distribuição dos periódicos, por unidade federativa.

Org.: o próprio autor.

$\mathrm{Na}$ sequência a essa verificação de dados foi iniciado o processo para a realização da categorização, que teve como princípio a associação por palavras. Considerou-se para esta tarefa as palavras-chaves informadas nos artigos. Contudo, fez-se necessário descartar tal abordagem haja vista não ser possível realizar as devidas categorizações e unitarizações de maneira qualitativa.

Por esforço de mostrar o quantitativo dos resultados, ao todo foram contabilizadas 5.130 palavras-chaves, das quais muitas se repetem e/ou modificam a relação singular/plural e flexão de gênero. Assim, foi possível obter 1.670 termos distintos. Faz-se importante mencionar que 155 artigos não possuíam palavras-chave informadas, todos estes com datação anterior a década de 1990, em que muitos periódicos não colocavam nas normas de formatação essa exigência.

As palavras-chave que mais incidiram estão: ensino de Geografia, com 353, seguido por Geografia (265), prática pedagógica (149), ensino (148), educação ambiental (95), educação (93), formação de professores (93), Geografia escolar (74), livros didáticos (70) e currículo (45).

Ao se considerar que tais dados quantitativos, expressos até o momento, não trazem consigo a exclusão mútua dos dados apresentados, nem a homogeneidade, a pertinência, a 
objetividade e fidelidade, bem como a produtividade do tratamento das informações, este pesquisador optou-se por tratamento qualitativo dos resultados obtidos, com base na AC, de Bardin (1977; 2011), com a presença do metatexto (MORAES, 2003), conforme se apresenta no tópico a seguir.

\section{b. Tratamento qualitativo dos resultados}

A análise qualitativa dos dados está dividida em categorias a priori (previamente estabelecidas) e categoria emergente (por demanda posterior ao processo de categorização inicial). $\mathrm{Na}$ sequência foram realizadas as considerações gerais acerca deste tratamento.

\section{Categorias a priori}

\section{Quadro 4 - Categoria 1: Políticas Educacionais}

CATEGORIA 1 POLÍTICAS EDUCACIONAIS

As políticas governamentais destinadas à escola em nosso país possuem algumas singularidades, pois, podem ser representadas pela construção de um currículo instrumental ou de resultados imediatos, demarcado por uma aglomeração de tópicos mínimos necessários ao trabalho, reunido ao currículo de convívio e apoio social, buscando a inserção no atendimento da diversidade social, almejando assim, a criação de um modelo de cidadania amparado na solidariedade e na redução das desordens sociais. Neste sentido, compõem-se nesta abordagem curricular, também, as mais variadas modalidades de educação, além do próprio ensino regular. Atrelada às diretrizes curriculares, a Educação Ambiental permeia as discussões presentes nos espaços escolares. O Plano Nacional do Livro Didático (PNLD) complementa as políticas públicas educacionais vigentes em nosso território. Outro aspecto que tem sido estimulado para os processos educativos está nas possibilidades de ensinagem em espaços não-formais, como, por exemplo, parques e museus.

\begin{tabular}{|c|c|c|}
\hline $\begin{array}{l}\text { UNIDADES DE } \\
\text { REGISTROS }\end{array}$ & DESCRIÇÃO DAS UNIDADES DE REGISTROS & $\begin{array}{c}\text { FREQUÊNCIA } \\
\text { RELATIVA }\end{array}$ \\
\hline $\begin{array}{c}\text { UR1 - } \\
\text { Modalidades de } \\
\text { Educação }\end{array}$ & $\begin{array}{l}\text { Ao tratar das modalidades de educação, buscou-se na Lei de Diretrizes e } \\
\text { Bases da Educação Nacional (LDBEN), n 9.394/96, em seu art. 21, as } \\
\text { definições e classificações, sendo: } \\
\text { Efetivamente, o Título V, com referência aos Níveis e das Modalidades de } \\
\text { Educação e Ensino, discorre sobre a Educação Básica (Cap. II), } \\
\text { englobando a Educação Infantil (Seção II), o Ensino Fundamental (Seção } \\
\text { III), o Ensino Médio (Seção IV), e a Educação de Jovens e Adultos (Seção } \\
\text { IV). O Título V ainda trata sobre a Educação Profissional (Capítulo III), a } \\
\text { Educação Especial (Cap. V). A estrutura composta pela organização da } \\
\text { educação no Brasil, se completa com o Título III, dispondo sobre as } \\
\text { Disposições Gerais. O mesmo possui diversos de dispositivos direcionados } \\
\text { à Educação Indígena e à Educação a Distância. }\end{array}$ & $32 \%$ \\
\hline $\begin{array}{c}\text { UR2 - Educação } \\
\text { Ambiental }\end{array}$ & $\begin{array}{l}\text { A realização da Conferência das Nações Unidas com o tema voltado ao } \\
\text { Ambiente Humano na capital sueca Estocolmo em } 1972 \text { representou o } \\
\text { primeiro passo para a implantação da Educação Ambiental. Pela primeira } \\
\text { vez discutiu-se de maneira mais abrangente sobre a obrigação da inserção } \\
\text { da dimensão ambiental na educação. Na Conferência Intergovernamental } \\
\text { Sobre a Educação Ambiental, realizada em outubro de } 1977 \text { em Tbilisi, na } \\
\text { Geórgia, foram estabelecidas estratégias e medidas que permanecem em } \\
\text { vigor até os dias atuais. }\end{array}$ & $27 \%$ \\
\hline UR3 - Currículo & $\begin{array}{l}\text { O currículo representa um dos meios mais significativos, já que é o ponto } \\
\text { onde podem ser reunidos saber e poder; representação e domínio; } \\
\text { argumentação e regulação. É exatamente nele que são reunidas as relações } \\
\text { de poder, extremamente relevantes no desenvolvimento de criação das } \\
\text { abstrações sociais. Pode-se afirmar, assim, que currículo, poder e } \\
\text { identidades sociais estão mutuamente atrelados. O currículo corporifica } \\
\text { relações sociais (SILVA, 1996). }\end{array}$ & $23 \%$ \\
\hline
\end{tabular}




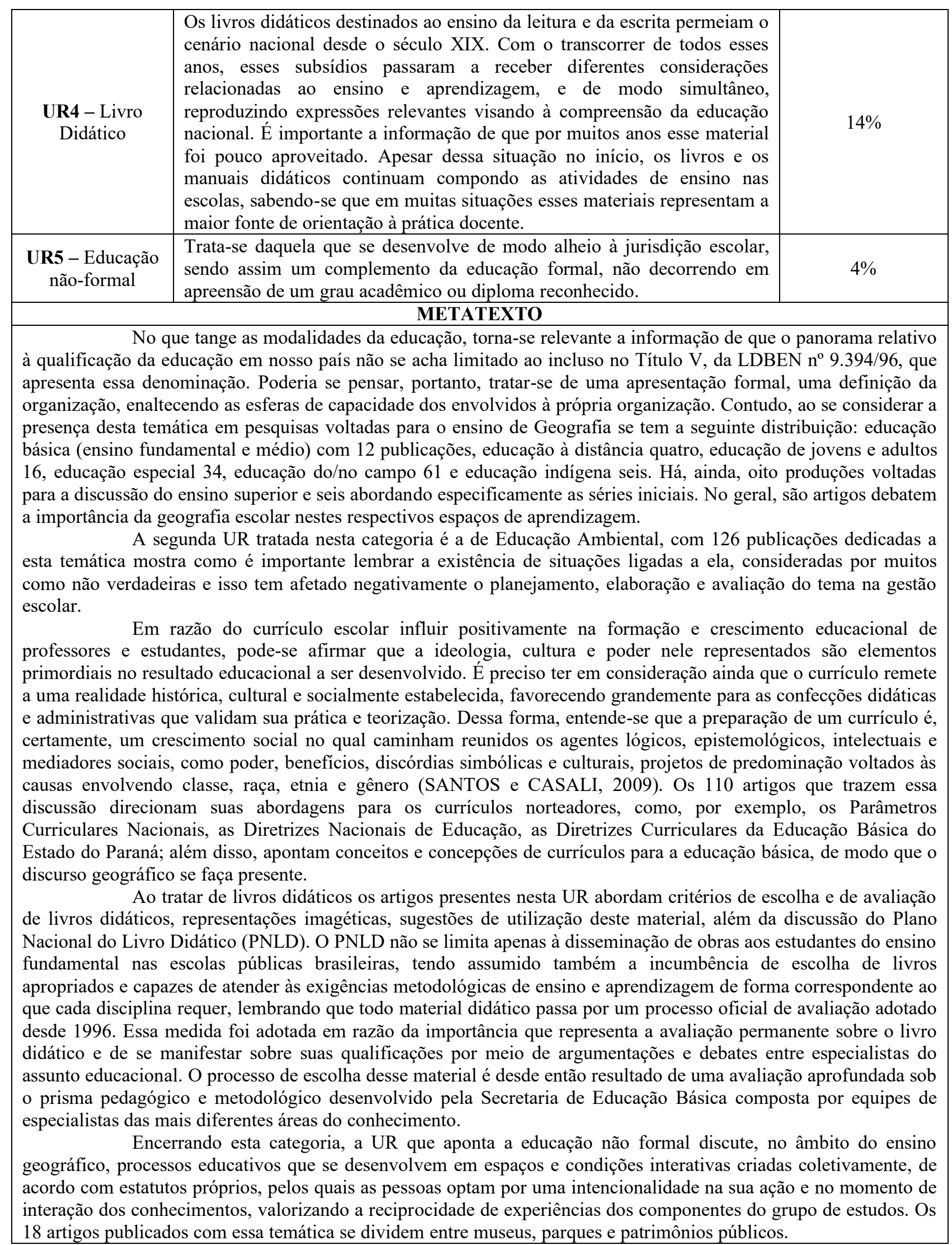

Org.: o próprio autor. 


\section{Quadro 5 - Categoria 2: Processos de Ensino e de Aprendizagem}

\section{CATEGORIA 2 PROCESSOS DE ENSINO E DE APRENDIZAGEM}

Essa categoria remete a uma integração dialógica que envolve o instrutivo e o educativo que tem como finalidade principal ajudar na formação integral da índole do educando. $\mathrm{O}$ instrutivo representa um recurso destinado à formação de seres humanos e prontos para exercerem sua cidadania. Por cidadão crítico reconhece-se aquele que, diante de uma situação tida como complexa se mostre preparado para não apenas enfrentá-la, mas também solucionála. Sua inteligência deve estar em constante evolução e essa condição só se dará se ele for preparado com o benefício de atividades lógicas. $\mathrm{O}$ educativo é obtido mediante a formação de valores, aptidões sensitivas que reconhecem o homem como ser social, entendendo a expansão de segurança, aspirações e outros ingredientes de âmbito volitivo e emocional que de maneira aliada à cognição facilitam o crescimento do saber, almejando ao final talhar a personalidade do cidadão.

A eficiência dos processos de ensino e de aprendizagem se enquadra na solução dada à apoderação dos conhecimentos, à evolução intelectual e física do discente, à criação de sensibilidades, qualificações e valores , capazes de atingir as ambições próprias e abrangentes almejadas em cada grau do ensino de diferentes instituições, levando a uma condição transformadora, que facilite as práticas comuns, a solidariedade e convivência comunitária. $\mathrm{O}$ entendimento de que o desenvolvimento do ensino e da aprendizagem representa uma ação lógica envolvendo a instrução e a educação, podendo ser reunida ao ideal de que semelhante distinção persiste entre a arte de ensinar e aprender. Essa conexão leva a uma noção de que o ensino e a aprendizagem possuem um funcionamento estruturado, formado por ingredientes efetivamente interligados. Pode-se afirmar assim que o resultado dos processos de ensino e de aprendizagem é o conhecimento.

Com base nesse fundamento, é possível entender que o conhecimento pode ser explicado como sendo uma obra social, requerendo avaliar o conjunto de ganhos econômicos, políticos e sociais. Pensando na criação de perspectivas de independência por meio dos processos de ensino e de aprendizagem, é importante que os professores assimilem a causa dos questionamentos dos quais estão diante, assumindo o papel de sujeito na organização desses processos.

\begin{tabular}{|c|c|c|}
\hline $\begin{array}{c}\text { UNIDADES DE } \\
\text { REGISTROS }\end{array}$ & DESCRIÇÃO DAS UNIDADES DE REGISTROS & $\begin{array}{c}\text { FREQUÊNCIA } \\
\text { RELATIVA }\end{array}$ \\
\hline $\begin{array}{l}\text { UR1 - Recursos } \\
\text { didáticos- } \\
\text { pedagógicos }\end{array}$ & $\begin{array}{l}\text { Acerca dessa UR, Souza }(2007, \text { p. 111) esclarece que "recurso didático } \\
\text { é todo material utilizado como auxílio no ensino-aprendizagem do } \\
\text { conteúdo proposto para ser aplicado pelo professor a seus alunos". Faz- } \\
\text { se importante mencionar que os recursos didáticos compõem uma gama } \\
\text { de ingredientes e técnicas pedagógicas que são empregadas como } \\
\text { sustentação experimental na realização das aulas e no processo de } \\
\text { crescimento de ensino e de aprendizagem, reforçando que os mesmos } \\
\text { são utilizados como fontes de estimulação do interesse da } \\
\text { aprendizagem pelos estudantes. }\end{array}$ & $60 \%$ \\
\hline $\begin{array}{l}\text { UR2 - Tecnologias } \\
\text { Digitais de } \\
\text { Informação e de } \\
\text { Comunicação }\end{array}$ & $\begin{array}{l}\text { Quando o tema envolve as Tecnologias Digitais de Informação e } \\
\text { Comunicação (TDIC), o assunto remete às tecnologias oriundas do } \\
\text { processo e produtos direcionados aos conhecimentos provindos da } \\
\text { eletrônica e das telecomunicações (KENSKI, 2007, p. 25). } \\
\text { Conforme explicação de Kenski (2007, p. 44), "a tendência é que com } \\
\text { o advento das modernas tecnologias, novas técnicas de mediações e } \\
\text { abordagens sejam introduzidas no ensino e aprendizagem visando à } \\
\text { apreensão dos conteúdos pelos educandos". Existe a expectativa de que } \\
\text { grande parte ou até mesmo a maioria das inovações apresentadas no } \\
\text { processo educativo devam promover transformações substanciais no } \\
\text { ensino em nosso país. }\end{array}$ & $16 \%$ \\
\hline $\begin{array}{c}\text { UR3 - Trabalho de } \\
\text { Campo }\end{array}$ & $\begin{array}{l}\text { Sobre essa particularidade, é importante observar essas indicações: "A } \\
\text { aula de campo é um rico encaminhamento metodológico para analisar a } \\
\text { área de estudo (urbana ou rural), de modo que o aluno poderá } \\
\text { diferenciar, por exemplo, paisagem de espaço geográfico" } \\
\text { (CASTROGIOVANNI; CALLAI; KAERCHER, 1999, p. 99). É } \\
\text { preciso reforçar ainda que no trabalho de campo o estudante é } \\
\text { estimulado a pensar e enxergar a realidade, tendo por base um } \\
\text { conhecimento prático e pessoal. "Parte-se de uma realidade local, bem } \\
\text { delimitada para se investigar a sua constituição histórica e as } \\
\text { comparações com os outros lugares, próximos ou distantes" } \\
\text { (CASTROGIOVANNI; CALLAI; KAERCHER, 1999, p. 99). }\end{array}$ & $8 \%$ \\
\hline UR4 - Didática & $\begin{array}{l}\text { A didática pode ser definida por um espaço do conhecimento com foco } \\
\text { na contemplação voltada ao processo de ensino, vista como sendo uma } \\
\text { prática social, independente de uma correta aplicação de normas e } \\
\text { procedimentos. Por esse ponto de vista, a didática da Geografia procura }\end{array}$ & $7 \%$ \\
\hline
\end{tabular}




\begin{tabular}{|c|c|c|}
\hline & $\begin{array}{l}\text { investigar a estrutura do ensino dessa disciplina: ingredientes } \\
\text { constitutivos, possibilidades de realização, conjunturas e sujeitos, } \\
\text { limites e demandas. Sua colaboração está em reproduzir maior } \\
\text { conhecimento do ensino e das bases teóricas e metodológicas da } \\
\text { Geografia escolar, suas origens epistemológicas, fomentando, dessa } \\
\text { maneira, a atividade docente consciente e autônoma (CAVALCANTI, } \\
\text { 2010). }\end{array}$ & \\
\hline UR5 - Avaliação & $\begin{array}{l}\text { Deve-se considerar a avaliação escolar como "[...] um meio e não um } \\
\text { fim em si mesma; está delimitada por uma determinada teoria e por } \\
\text { uma determinada prática pedagógica" (CALDEIRA, 2000, p. 122). Ao } \\
\text { professor, cabe, nesse processo o papel de avaliador, reconhecendo e } \\
\text { dando sentidos e importâncias à avaliação escolar, produzindo } \\
\text { conhecimentos e representações referentes à avaliação e sobre sua } \\
\text { função como avaliador, sustentado em suas próprias compreensões, } \\
\text { saberes e experiências. "Ela não ocorre num vazio conceitual, mas está } \\
\text { dimensionada por um modelo teórico de sociedade, de homem, de } \\
\text { educação e, consequentemente, de ensino e de aprendizagem, expresso } \\
\text { na teoria e na prática pedagógica" (CALDEIRA, 2000, p. 122). }\end{array}$ & $5 \%$ \\
\hline $\begin{array}{c}\text { UR6 - Teorias de } \\
\text { Aprendizagem }\end{array}$ & $\begin{array}{l}\text { A aprendizagem representa um desenvolvimento sequencial, podendo } \\
\text { acontecer em qualquer situação. Sendo assim, é possível afirmar que } \\
\text { uma das condições primordiais do aprendizado é a cultura, já ela } \\
\text { consegue adaptar o indivíduo em consequência de suas ligações com o } \\
\text { meio. Por esse entendimento, a aprendizagem provoca no indivíduo } \\
\text { uma transformação por meio de sua própria experiência (LA ROSA, } \\
\text { 2003). É preciso ressaltar que a pessoa pode experimentar } \\
\text { transformações alheias à sua aprendizagem, mas em razão das } \\
\text { manifestações decorrentes de sua maturidade, como ao absorver a } \\
\text { linguagem, engatinhar e andar. É possível ocorrer outras } \\
\text { transformações, como no caso de acometimento de doenças físicas, } \\
\text { neurológicas ou psicológicas. }\end{array}$ & $3 \%$ \\
\hline $\begin{array}{c}\text { UR7 - Psicologia da } \\
\text { Educação }\end{array}$ & $\begin{array}{l}\text { Ao se considerar o papel do conhecimento psicológico na educação é } \\
\text { importante ter em mente o passado e as diferentes promessas teóricas } \\
\text { da Psicologia, agindo para dirimir os questionamentos educacionais na } \\
\text { atualidade. }\end{array}$ & $1 \%$ \\
\hline \multicolumn{3}{|c|}{$\begin{array}{ll} & \text { METATEXTO } \\
\end{array}$} \\
\hline \multicolumn{3}{|c|}{ 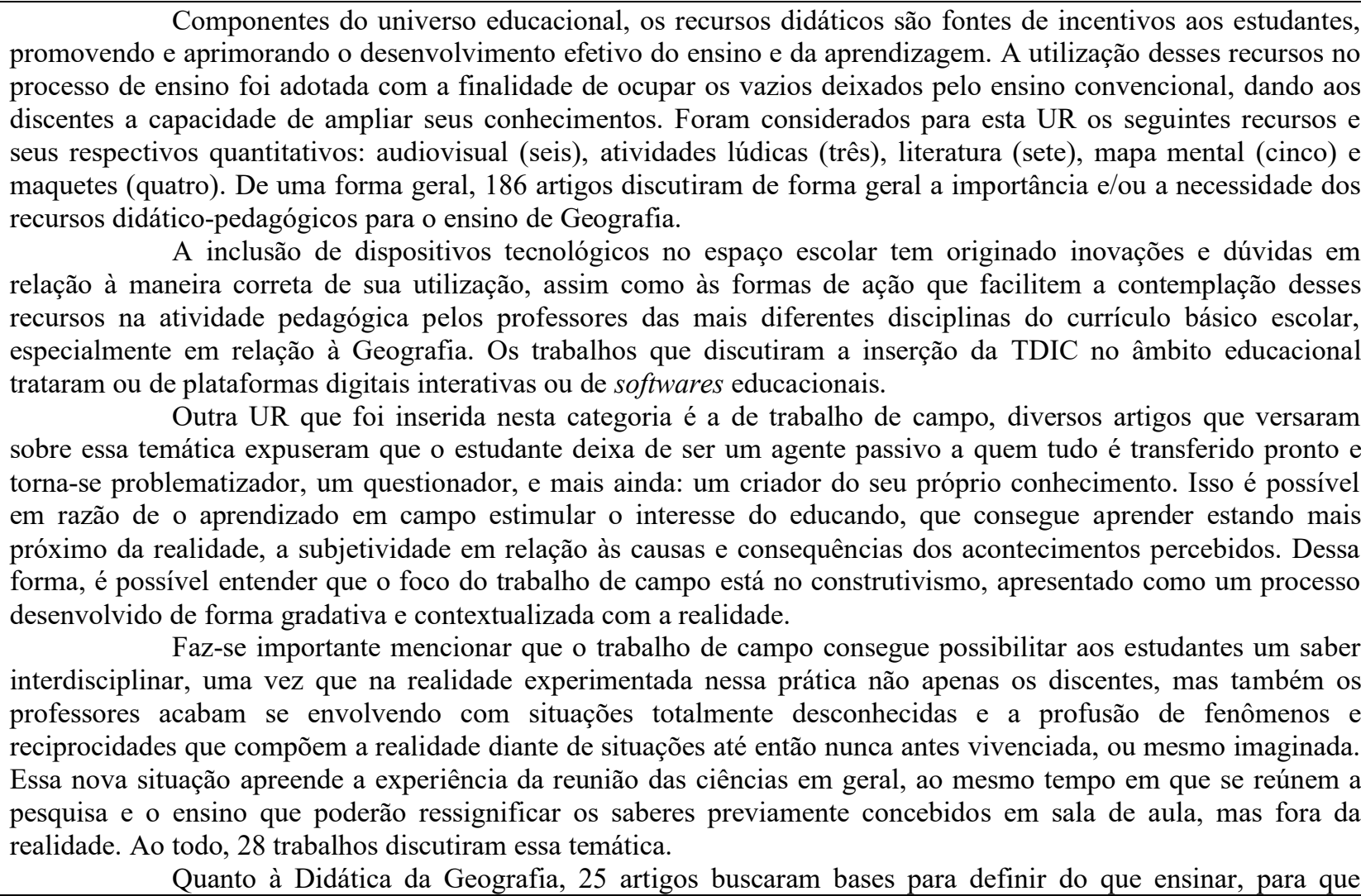 } \\
\hline
\end{tabular}


ensinar, para quem ensinar, o professor pode se valer de várias sugestões: de um lado, os conhecimentos geográficos acadêmicos, não apenas da Geografia acadêmica, mas também da Didática da Geografia e de outro, pode se valer da Geografia escolar, já totalmente estruturada pela escola há anos.

Dessa forma, ainda a respeito da UR da Didática, pode-se afirmar que para ensinar conteúdos de geografia, com o benefício dos conhecimentos escolares, exige-se uma comunicação real, pela qual estudantes e professores, estão habilitados a se manifestar, baseados nas argumentações sobre temas relevantes e no embate envolvendo entendimentos, experiências, análises, visando à criação de um verdadeiro sentido das expressões repassadas para os discentes. As dificuldades apresentadas pelos professores têm recebido atenção por parte de vários setores do conhecimento educacional, especialmente pela Didática e as didáticas das disciplinas exclusivas (CAVALCANTI, 2010).

Acerca da avaliação é importante o entendimento de que ela está intimamente atrelada à natureza do conhecimento, e em razão da legitimidade dessa natureza, a avaliação deverá unir-se a ela se quiser ser fiel preservando essa coesão epistemológica. Seguindo essa acepção, 17 artigos que discutiram acerca dessa temática partiram do entendimento de que a avaliação, enquanto prática escolar, não representa uma atividade imparcial, ou apenas técnica, ou seja, não acontece num vazio conceitual, sendo, sim, reconhecida por um modelo teórico de mundo, de ciência e de educação, transposta em prática pedagógica. Uma segunda interpretação a vê como uma prática de avaliação dos processos de ensino e de aprendizagem que se dá por intermédio da conexão pedagógica entre as intencionalidades de ação, centradas em comportamentos, posicionamentos e competências dos envolvidos.

As Teorias de Aprendizagem podem ser classificadas em: behavioristas, construtivistas ou humanistas. Todos os 10 artigos que trataram desta temática se pautaram em teorias construtivistas, principalmente na Teoria de Aprendizagem Significativa, de Ausubel. De modo geral, a aprendizagem representa uma transformação que também pode se dar em decorrência das experiências da pessoa, lembrando, porém, que para ser comprovada como tal, é preciso ser constatada a solidez, isto é, ela precisa estar incorporada de forma definitiva na pessoa. Ocorre, contudo, que um grande número de pessoas acaba misturando construção do conhecimento com aprendizagem. É importante lembrar que aprender significa algo bem mais abrangente, sendo a forma de a pessoa aumentar seu conhecimento.

A última UR desta categoria pertence aos artigos que abordaram a temática de Psicologia da Educação, com ênfase na psicogênese e na cognição para a aprendizagem em Geografia. A grandeza da atribuição direcionada à Psicologia na Educação no futuro não pode ser dimensionada de imediato, havendo a necessidade de uma compreensão psicológica mais aprofundada sobre a própria natureza humana.

Org.: o próprio autor.

\section{Quadro 6 - Categoria 3: Conteúdos da Geografia}

CATEGORIA 3 CONTEÚDOS DA GEOGRAFIA

Os conteúdos representam os frutos produzidos por uma criação dotada de sentido social enquanto conhecimento, expondo uma fatia de conhecimento provindo da cultura e que precisa ser ofertado como conteúdo ao educando, visando à sua adequação e aplicação, sendo esse, portanto, o conhecimento estabelecido. É preciso ainda que, além desse conhecimento já definido, persista, no procedimento destinado ao ensino e a aprendizagem, uma atenção constante quanto à obrigação do conhecimento, pois na natureza há fenômenos e relações que a capacidade humana ainda não conseguiu atingir.

\begin{tabular}{|c|c|c|}
\hline $\begin{array}{l}\text { UNIDADES DE } \\
\text { REGISTROS }\end{array}$ & DESCRIÇÃO DAS UNIDADES DE REGISTROS & $\begin{array}{c}\text { FREQUÊNCIA } \\
\text { RELATIVA }\end{array}$ \\
\hline UR1 - Cartografia & $\begin{array}{l}\text { Pode-se reconhecer as vias metodológicas voltadas ao aprimoramento } \\
\text { das aptidões importantes para conseguir elaborar e decifrar mapas e } \\
\text { gráficos de modo eficaz, como codificar e decodificar os ícones, obter } \\
\text { informações e desvendar a espacialidade ou sequência de ingredientes } \\
\text { necessários à compreensão geográfica (PASSINI, 2012). No curso da } \\
\text { construção do saber existem diferentes maneiras de estudar o local e } \\
\text { explorar o espaço habitado, fazendo com que o estudante possa se sentir } \\
\text { parte de um todo. }\end{array}$ & $48 \%$ \\
\hline $\begin{array}{c}\text { UR2 - Geografia } \\
\text { Humana }\end{array}$ & $\begin{array}{l}\text { Por Geografia Humana entende-se a ciência que se dedica ao estudo e à } \\
\text { comunicação que envolve sociedade e espaço. É interessante mencionar } \\
\text { que ela favorece grandemente para o ser humano obter noção do espaço } \\
\text { geográfico no qual habita. }\end{array}$ & $30 \%$ \\
\hline $\begin{array}{c}\text { UR3 - Geografia } \\
\text { Física }\end{array}$ & $\begin{array}{l}\text { Esta UR remete ao estudo das propriedades naturais presentes na } \\
\text { superfície terrestre, sendo então o estudo das condições da natureza que } \\
\text { podemos identificar como paisagem natural. }\end{array}$ & $19 \%$ \\
\hline $\begin{array}{l}\text { UR4 - } \\
\text { Inter/Multi/Trans } \\
\text { Disciplinaridade }\end{array}$ & $\begin{array}{l}\text { São como técnicas que buscam agrupar as chances de criação de } \\
\text { saberes, próprio de cada área, como: } \\
\text { Interdisciplinaridade:- Intercâmbio comum e comunicação entre } \\
\text { diferentes conhecimentos, de maneira recíproca e disposta } \\
\text { ordenadamente; objetivos metodológicos comuns a todos; integração } \\
\text { dos resultados, preservação dos ganhos particulares de cada disciplina, }\end{array}$ & $3 \%$ \\
\hline
\end{tabular}


almejando, contudo, o encontro de soluções para seus questionamentos por meio da conexão entre disciplinas.

Multidisciplinaridade:- mais de uma disciplina: sem ligação com outra disciplina. Cada uma preserva sua metodologia própria, não havendo possibilidade para resultado conjunto. De acordo com Piaget, isso ocorre quando a solução de uma questão exige a apreensão de dados de uma ou mais ciências ou subdivisões do conhecimento, sem que as disciplinas envolvidas sofram qualquer alteração.

Transdisciplinaridade:- etapa com maior importância que a interdisciplinaridade, não afetando, porém, as conexões recíprocas, mas acomodando essas relações no âmbito de um conjunto total; interação global das diversas ciências; em razão de sua inovação, não permite divisão das matérias.

\section{METATEXTO}

Quanto a cartografia escolar, 138 artigos compuseram essa UR. As abordagens presentes na maioria deles (131) oferecem formas de se utilizar a linguagem cartográfica para os professores possibilitarem aos estudantes a prática adequada para o entendimento do espaço geográfico, auxiliando na apreensão das demarcações usadas para identificar o mesmo, por meio da alfabetização cartográfica. O crescimento do entendimento do que representa o espaço e os itens nele inclusos, exige uma profunda preparação aliada às práticas de demarcações e decodificações do espaço no qual a criança convive. Os demais artigos abordam exemplos de Sistemas de Informações Geográficas (SIG) para o ensino de Geografia.

A segunda e a terceira UR apresentadas nesta categoria abordam conteúdos específicos da Geografia, expressando uma das maiores discussões dicotômicas presentes na ciência geográfica: Geografia Humana e Geografia Física, com destaques para Geografia Urbana e Geografia Agrária, para a UR2, e Geomorfologia e Climatologia para a UR3.

Propostas multi e transdisciplinares apareceram uma vez cada, enquanto a abordagem interdisciplinar contou com seis publicações. Os trabalhos presentes nesta UR são pautados mais pelos discursos destas abordagens do que pelas ações práticas no ambiente escolar.

\section{Org.: o próprio autor.}

\section{Quadro 7 - Categoria 4: Ciência Geográfica}

\section{CATEGORIA 4 CIÊNCIA GEOGRÁFICA}

O domínio da natureza científica da Geografia é capaz de acrescentar ainda mais aquilo que os geógrafos conseguem explicar, inclusive aprimorando a criação intelectual dos mesmos, principalmente o que se almeja aqui, reforçando a preparação de futuros profissionais dessa tradicional disciplina, podendo nos agraciar com jovens contemplando a ciência socioespacial-socioambiental de maneira robusta.

Torna-se necessariamente importante ter sempre em mente que a Geografia Moderna, tida como tradicional, teve seus primeiros mestres valorizados na Alemanha e posteriormente na França, lembrando que persiste certa tendência do Positivismo na Geografia Tradicional. A Escola Alemã foi reconhecida em razão de sua distinção Determinista, sendo seu maior nome Friedrich Ratzel. Em posição contrária ao determinismo alemão, inicia-se na França o Possibilismo, tendência que teve em Vidal de La Blache seu grande defensor, consolidando a Escola Francesa de Geografia. Essas duas escolas são reconhecidas como as maiores influenciadoras no período da Geografia Tradicional (MORAES, 2005).

A partir dos anos de 1950 começaram a surgir mobilizações no sentido de se renovar a Geografia. Contudo, esses "movimentos" ou "correntes" não conseguem apresentar uma unidade, sugerindo inovações na geografia, até mesmo com propostas contrárias, não havendo unanimidade entre elas. Essa situação é consequência da variedade de técnicas de interpretação, muitas vezes empregada para a explanação do que já se sabe e ainda enaltecendo posicionamentos, notadamente políticos, ideológicos e filosóficos dos componentes das correntes (MORAES, 2005).

Faz-se possível também reunir as tendências geográficas de renovação, da Geografia Contemporânea, numa escala esquemática, assim distribuída: Geografia Teórico-Quantitativa, alicerçada no neopositivismo; Geografia da Percepção e do Comportamento, numa linha voltada à fenomenologia; Geografia Ecológica, desprovida de um traço filosófico claro; e Geografia Crítica ou Radical, criada sob as estruturas da dialética materialista (MORAES, 2005).

\begin{tabular}{|c|c|c|}
\hline $\begin{array}{l}\text { UNIDADES DE } \\
\text { REGISTROS }\end{array}$ & DESCRIÇÃO DAS UNIDADES DE REGISTROS & $\begin{array}{c}\text { FREQUENNCIA } \\
\text { RELATIVA }\end{array}$ \\
\hline $\begin{array}{l}\text { UR1 - História e } \\
\text { Correntes do } \\
\text { Pensamento } \\
\text { Geográfico }\end{array}$ & $\begin{array}{l}\text { Os diferentes "fazeres geográficos" ou sugestões geográficas, como: } \\
\text { Geografia Crítica (Dialética Materialista), Geografia da Percepção e } \\
\text { Comportamento (ou mesmo Geografia da Percepção, Geografia } \\
\text { Humanística, Geografia Cultural, Geografia Histórica); Geografia } \\
\text { Teórico-Quantitativa (Neopositivismo), Geografia Ecológica. Há } \\
\text { ainda outras que certamente serão criadas dentro da nova dinâmica }\end{array}$ & $38 \%$ \\
\hline
\end{tabular}




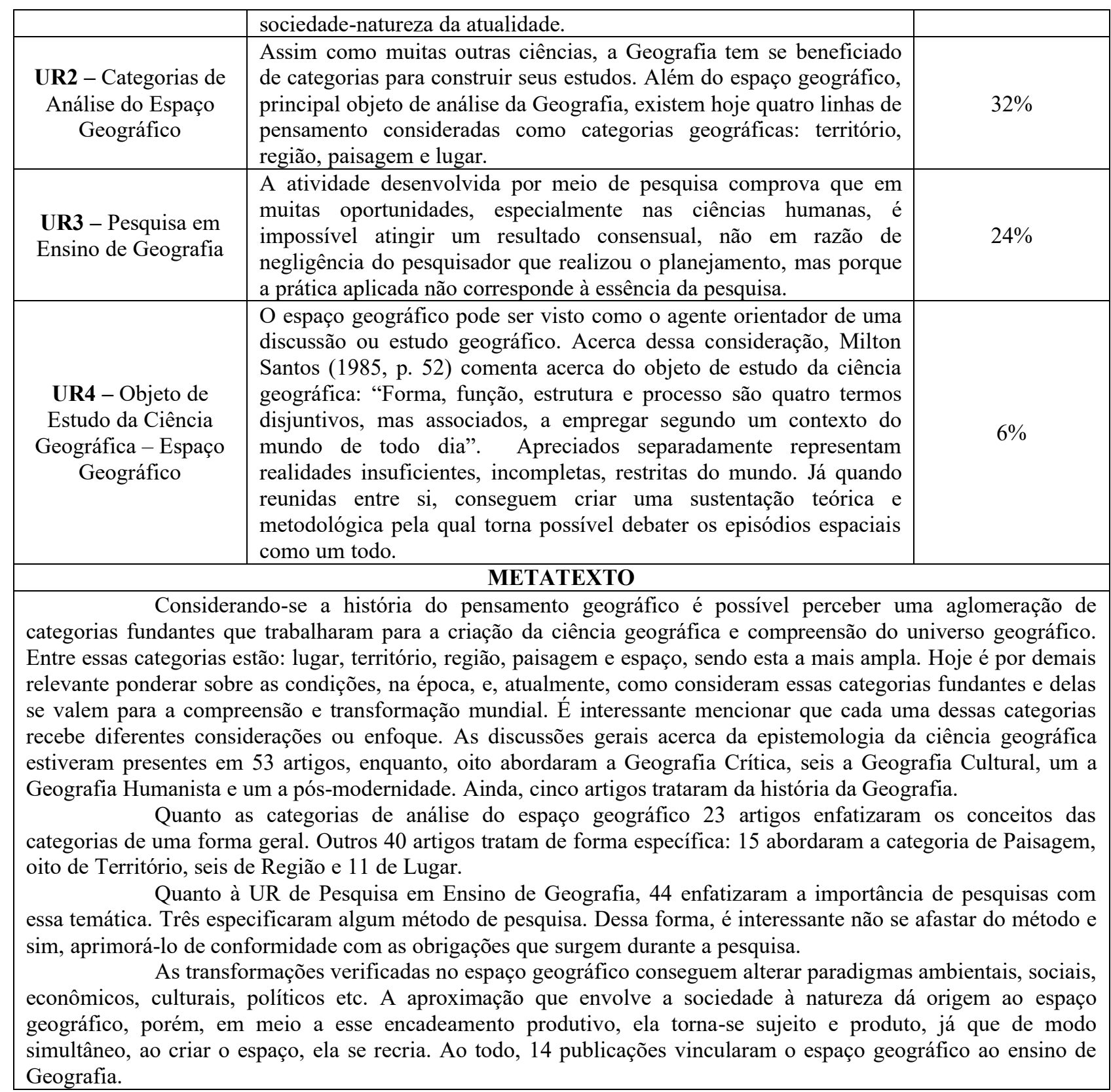

Org.: o próprio autor.

\section{Quadro 8 - Categoria 5: Formação de Professores}

CATEGORIA 5 FORMAÇÃO DE PROFESSORES

A formação de professores de Geografia visa à criação de perspectivas para exercer suas aptidões educacionais, possíveis por meio de leituras, princípios, aprendizados, vivência, reflexão e prática, condições que o nortearão na condução do crescimento educativo dos educandos.

Todo o processo de crescimento da preparação de professores requer a inclusão de uma reflexão acerca do próprio desenvolvimento de ensino e de aprendizagem, atentando-se para as hipóteses subentendidas, convicções e condutas, em meio a um processo contínuo de autoavaliação e de objetivos intelectuais, dando ao professor a chance de se reconhecer, e, por conseguinte, conhecer o seu educando.

Os conhecimentos possuídos pelos professores e a experiência pedagógica se acham especialmente reunidos, já que é no desempenho dessa experiência educacional que uma nação é edificada pelo professor, a começar pela demonstração de uma técnica estimuladora de aquisição de conhecimentos.

Argumentando sobre esse tema, Pimenta (1999) entende ser muito importante o professor ter ideia da grandeza que representa a atitude ponderada como desenvolvida por meio da sua experiência pedagógica, reforçando ainda que essa ponderação deve dar origem a uma tríplice movimentação: da reflexão na ação, da reflexão decorrente da ação e da reflexão referente à reflexão na ação. Em estudo de 1999, Pimenta defende a ideia de que essa capacidade de conhecer e avaliar a própria atividade diária certamente facilitará para tornar o professor em um profissional independente e pronto para promover o crescimento da prática educacional. 


\begin{tabular}{|c|c|c|}
\hline $\begin{array}{l}\text { UNIDADES DE } \\
\text { REGISTROS }\end{array}$ & DESCRIÇÃO DAS UNIDADES DE REGISTROS & $\begin{array}{l}\text { FREQUÊNCIA } \\
\text { RELATIVA }\end{array}$ \\
\hline $\begin{array}{l}\text { UR1 - Formação } \\
\text { Inicial }\end{array}$ & $\begin{array}{l}\text { Com referência à docência, a LDBEN, } n^{\circ} 9.394 / 96 \text {, em seu capítulo } \mathrm{V} \text {, } \\
\text { Inciso VI, abordando sobre os profissionais da educação, expõe uma } \\
\text { distribuição de definições. No parágrafo Único do Art. } 61 \text {, ao se referir às } \\
\text { especificidades inclusas na preparação de professores, a transcrição do } \\
\text { mesmo estabelece que "[...] a presença de uma sólida formação básica, que } \\
\text { propicie o conhecimento dos fundamentos científicos e sociais de suas } \\
\text { competências de trabalho [...]" (Inciso I), a "[...] associação entre teorias e } \\
\text { prática, mediante estágios supervisionados e capacitação em serviço [...]" } \\
\text { (Inciso II) e "[...] o aproveitamento da formação e experiências anteriores, } \\
\text { em instituiçcões de ensino e em outras atividades [...]". (Inciso III). }\end{array}$ & $90 \%$ \\
\hline $\begin{array}{c}\text { UR2 - Saberes } \\
\text { Docentes }\end{array}$ & $\begin{array}{l}\text { Por saber docente, entende-se um "saber plural, formado de diversos } \\
\text { saberes provenientes das instituições de formação, de formação } \\
\text { profissional, dos currículos e da prática cotidiana" (p. 54). Com base nesse } \\
\text { pensamento de diversidade, Tardif (2002) argumenta que a perspectiva de } \\
\text { uma avaliação condizente com os conhecimentos docentes só é possível } \\
\text { quando reunida à essência de suas origens, aos princípios de sua absorção } \\
\text { e às conexões que os professores instituem entre os seus conhecimentos e } \\
\text { com os mesmos. } \\
\text { Em estudo de } 2002 \text {, Tardif expressa a presença de quatro categorias } \\
\text { distintas de conhecimentos envolvidos na pratica docente, sendo as } \\
\text { mesmas: os conhecimentos apreendidos da formação profissional (das } \\
\text { ciências da educação e da ideologia pedagógica); os conhecimentos } \\
\text { disciplinares; os conhecimentos curriculares e, ainda os chamados } \\
\text { experienciais. }\end{array}$ & $8 \%$ \\
\hline $\begin{array}{c}\text { UR3 - Formação } \\
\text { Continuada }\end{array}$ & $\begin{array}{l}\text { De acordo com Gatti (1997), cursos desenvolvidos após a graduação, } \\
\text { atividades gerais vistas como oportunidade de facilitar o crescimento } \\
\text { profissional, como assembleias pedagógicas, envolvimento na } \\
\text { administração escolar, tempo dedicado às atividades coletivas na escola, } \\
\text { congressos, seminários e cursos de diversos modelos ofertados pelas } \\
\text { secretarias da educação ou outras instituições presenciais ou à distância } \\
\text { são hoje reconhecidos como de formação continuada, mesmo quando os } \\
\text { mesmos não conseguem reproduzir permutas. Nessa mesma tendência } \\
\text { tecnicista, persiste a obrigação do estabelecimento de horas de preparação } \\
\text { continuada aos professores de muitas secretarias de educação, como } \\
\text { obrigação requerida para progressão funcional. }\end{array}$ & $2 \%$ \\
\hline \multicolumn{3}{|c|}{ METATEXTO } \\
\hline \multicolumn{3}{|c|}{$\begin{array}{l}\text { Essa categoria aponta a divisão dos } 146 \text { artigos em três UR, sendo que } 90 \% \text { destes estão voltados para } \\
\text { a formação inicial de professores de Geografia. } 23 \text { artigos trataram especificamente do estágio supervisionado. } \\
\text { De acordo com Zabala (1998) os conhecimentos adquiridos pelos professores são plurais, } \\
\text { heterogêneos, pois são capazes de produzir, na própria realização do trabalho, saberes e exposições do saber-fazer e } \\
\text { conhecimento absorvidos por intermédio de várias origens que agregam saberes, domínios, habilidades e os } \\
\text { procedimentos demonstrados pelos professores no âmbito de suas práticas profissionais, propondo mudanças } \\
\text { inovadoras, novas ações e reordenações. Os saberes adquiridos pelos professores, tão imprescindíveis à atividade } \\
\text { educacional, compóem uma agregação de conhecimentos adquirida por intermédio de diferentes origens, como as } \\
\text { indicações de matérias curriculares, livros didáticos e disciplinas ministradas. Tardif (2002) divide esses saberes em } \\
\text { quatro categorias, definidas da seguinte forma: disciplinares, curriculares, profissionais e de experiência. } \\
\text { Essas demarcações estabelecidas por Tardif (2002) são corroboradas por Borges (2004, p 26) } \\
\text { acrescentando que "[...] os professores não se apoiam em um saber para ensinar, mas em vários", lembrando, no } \\
\text { entanto, que Tardif (2002) menciona uma importante característica presente entre os conhecimentos criados no } \\
\text { universo da atividade docente e os demais, em decorrência das ordenações formadoras ou mesmo das programas } \\
\text { curriculares, reproduzidos com base na experiência. Por esse entendimento, o conhecimento absorvido por meio da } \\
\text { experiência é reconhecido como relevante por Tardif (2002, p. 39) quando afirma que "os docentes, no exercício de } \\
\text { suas atribuições e na prática e na própria atividade conseguem processar saberes característicos, fundamentados em } \\
\text { sua lida diária e no conhecimento de seu meio [...] oriundos da experiência e validados por ela". } \\
\text { Quanto à formação continuada, apenas três artigos fizeram essa discussão, isto é, a necessidade de } \\
\text { continuar constantemente no processo de capacitação docente. }\end{array}$} \\
\hline
\end{tabular}

Org.: o próprio autor. 


\section{Categorias emergentes}

\section{Quadro 9 - Categoria 6: Sujeitos da Educação}

\section{CATEGORIA 6 SUJEITOS DA EDUCAČ̃̃O}

Instituições de ensino por seus espaços físicos, em decorrência de suas instalações localizadas em construções elevadas, pátios amplos e salas superlotadas, aptas para acolherem pessoas gabaritadas que exercem suas atribuições profissionais e ainda outras pessoas que precisam do local para se prepararem e se formarem.

Ocorre, contudo, que muito mais do que edificações físicas, as escolas são sim, locais comprometidos com a criação e construção coletiva e prática de bons projetos pedagógicos e também com o cumprimento do que manda os regimentos internos, visando à facilitação de sua missão junto à comunidade na qual se encontra e à sociedade como um todo.

Deste modo, parte dessas construções coletivas são realizadas por docentes e discentes (como expressos nas UR a seguir). Diretores, equipe pedagógica, administrativa e da manutenção contribuem socialmente para a formação de uma escola, contudo, estes sujeitos não foram abordados nas pesquisas de ensino em Geografia.

\begin{tabular}{|c|c|c|}
\hline $\begin{array}{l}\text { UNIDADES DE } \\
\text { REGISTROS }\end{array}$ & DESCRIÇÃO DAS UNIDADES DE REGISTROS & $\begin{array}{c}\text { FREQUÊNCIA } \\
\text { RELATIVA } \\
\end{array}$ \\
\hline UR1 - Discentes & $\begin{array}{l}\text { Percepção do conhecimento geográfico, seja quanto ao objeto ou as } \\
\text { categorias de análise do espaço geográfico. Esta UR também aborda da } \\
\text { identidade e a percepção do estudante quanto a realidade a qual o } \\
\text { mesmo está inserido e vivencia diuturnamente. }\end{array}$ & $60 \%$ \\
\hline UR2 - Docentes & $\begin{array}{l}\text { Diversos fatores compõem a UR2, são eles: péssimas condições de } \\
\text { trabalho dos docentes, barreiras para o exercício da profissão, além da } \\
\text { desvalorização do papel do educador são pontos que contribui para } \\
\text { inúmeros problemas de saúde física, mental e emocional. }\end{array}$ & $40 \%$ \\
\hline \multicolumn{3}{|l|}{ METATEXTO } \\
\hline \multicolumn{3}{|c|}{$\begin{array}{l}\text { Nesta categoria estão presentes } 15 \text { artigos. Destes, nove estão relacionados aos estudantes e seis aos } \\
\text { professores. } \\
\mathrm{Na} \text { UR1, voltada aos discentes as problemáticas destes artigos tratam dos seguintes aspectos: } \\
\text { identidade, juventude, percepção e perfil. Enquanto na UR2, a discussão acerca do docente estão pautadas em dois } \\
\text { aspectos: a saúde do professor e os desafios da profissão. } \\
\text { Essas discussões especificam a Geografia quando, no caso dos estudantes, essas discussões se inserem } \\
\text { num contexto de aulas dessa ciência. No caso dos educadores, se pautam na especificidade do sujeito enquanto } \\
\text { professor de Geografia. }\end{array}$} \\
\hline
\end{tabular}

Org.: o próprio autor.

$\mathrm{Na}$ sequência, foram realizadas algumas considerações gerais acerca dos resultados obtidos, tanto os quantitativos quanto os qualitativos.

\section{c. Das considerações gerais}

O desenvolvimento do ensino de Geografia tem como fundamento possibilitar ao estudante do ensino regular a alfabetização geográfica e, somente após essa ação, desenvolver a reflexão e a análise, bem como a crítica do espaço geográfico. Deve-se permitir aos educandos compreender os saberes geográficos, reconhecendo-os como necessários, o mesmo devendo acontecer por parte do professor.

Com referência ao ensino de Geografia, e também dos demais elementos curriculares, é necessariamente importante aceitar a observação e a crítica que se apresentam atualmente à instituição escolar e aos cursos de formação de professores de Geografia, englobando-os no grupo político, social e econômico do mundo, especialmente em nosso país.

Sabendo não ser possível a criticidade sem um conhecimento do ser humano decorrente das obrigações com a sociedade, que se transforma de acordo com a época, pode-se admitir e aceitar 
a necessidade veemente do professor possuir um conhecimento pedagógico, que poderá determinar os processos de ensino e de aprendizagem no dia a dia de sua atividade. É inegável a incidência de novas possibilidades pedagógicas que surgem com o decorrer dos tempos, e essa ação requer do professor um conhecimento da teoria que poderá subsidiar sua ação pedagógica. Tais reflexões são possíveis por meio da pesquisa científica.

Desta forma, o processo metodológico da Geografia escolar gera reflexões quanto ao tratamento com as questões espaciais, destacam-se fatos e acontecimentos locais, regionais e/ou até mesmo globais, assim como a política educacional baseada na pedagogia da variação/transformação dos costumes e comportamentos dos estudantes, e dos professores também, para a produção do exercício da cidadania.

Dessa maneira, o (re) pensar a dimensão técnica, política e ética dos processos de ensino e de aprendizagem na geografia escolar e suas repercussões na sociedade precisam constituir o esforço das pesquisas em Ensino de Geografia.

Neste sentido, conforme figura 12, há uma concentração de pesquisas publicadas acerca de políticas educacionais e de processos de ensino e de aprendizagem, de modo que estes dois eixos correspondem a mais da metade de todos os artigos publicados a respeito dessa temática.

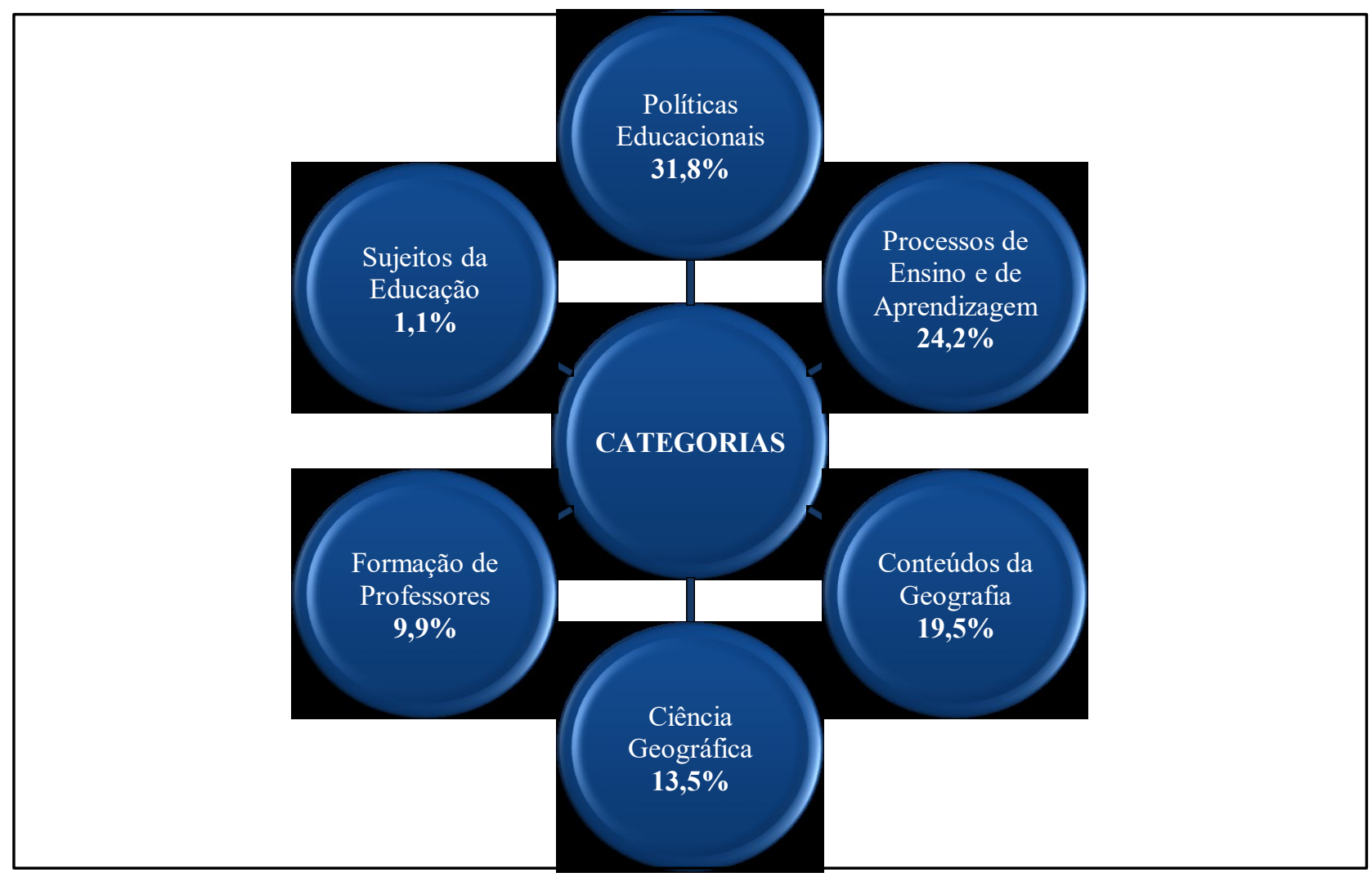

Figura 12 - Percentual da incidência de artigos em ensino de Geografia, por categoria. Org.: o próprio autor. 
Todas as temáticas possuem sua importância e seu papel dentro dos pilares das pesquisas em educação geográfica da qual fazem parte, entretanto, igualmente importante é promover pesquisas qualitativas acerca das categorias que possuem poucas publicações, com o objetivo de fortalecer, de modo homogêneo, todos os aspectos das pesquisas em ensino de Geografia.

\section{PARA NÃO CONCLUIR, MAS, SIM, AVANÇAR...}

O estudo relacionado ao ensino de Geografia aponta também a grandeza que representa a definição da sala de aula como sendo o espaço apropriado para reflexões e reivindicações do direito civil e político, da autonomia e da própria justiça social, reconhecendo a importância que representa a defesa da Geografia escolar como sendo o meio mais indicado para a construção da cidadania, podendo ser atribuído a ela sua real identidade, já que a mesma não se nega a uma grandeza ideológica e política. Daí a importância das pesquisas direcionadas ao Ensino Geográfico.

Neste sentido, resgata-se a questão problematizadora apontada no início deste manuscrito: "Com base nos artigos de ensino de Geografia publicados em periódicos nacionais, disponíveis de forma on line, quais as perspectivas e as tendências das pesquisas nesta área?”.

Desta forma, buscando dar a essas pesquisas um aperfeiçoamento em relação à sua distribuição, é importante que haja uma ação efetiva por parte das universidades espalhadas em todas as regiões do território nacional, dispondo as mesmas de recursos governamentais que certamente darão respaldo para o pesquisador desenvolver sua atividade.

Faz-se preciso lembrar, no entanto, que cabe também à academia estimular seus próprios membros a desenvolverem estudos relacionados ao ensino de Geografia, entendendo a importância que representa as universidades disporem de grande quantidade de estudos produzidos, condição que certamente facilitaria para melhor avaliação da própria instituição.

No que tange a resultados de pesquisa acerca da formação de professores muito se diz ser necessário ao docente ter, além do conhecimento total dos conteúdos, capacidade de raciocinar de forma coerente e harmoniosa, compreender os fenômenos que envolvem a realidade social e, além de tudo aqui exposto, consiga se colocar como componente facilitador dessa realidade, ou seja, o professor de Geografia precisa estar preparado para realizar o ensino de conteúdos de sua ciência.

Com base nas publicações investigadas o ensino geográfico tem vivido nas últimas décadas situações de mudanças transformadoras, não apenas em relação às ofertas pedagógicas inovadoras, mas também no que remete aos conteúdos inclusos nos livros didáticos. É possível verificar, no entanto, que são mínimas as transformações percebidas nas atividades educativas efetivas e na ordenação dos espaços escolares diante das possibilidades disponibilizadas atualmente. 
Todo o desenvolvimento da formação de professores exige que se inclua uma reflexão referente aos processos de ensino e de aprendizagem, observando teorias subentendidas, crenças e comportamentos, num crescimento permanente de autoavaliação e de finalidades intelectuais, possibilitando ao educador conhecer-se a si mesmo, e assim poder conhecer o seu educando.

Por meio de pesquisas, os conhecimentos docentes e a prática pedagógica estão essencialmente ligados, pois é no exercício da experiência docente que uma ação é desenvolvida, construída e reconstruída pelo professor, principiando numa atividade dinâmica ao ensinar.

Caminhando nessa mesma tendência, sabendo não ser possível preparar sem um conhecimento do ser humano decorrente das obrigações com a sociedade, que se transforma de acordo com a época, pode-se admitir e aceitar a necessidade veemente do professor possuir um conhecimento pedagógico, que poderá determinar o processo de ensino e de aprendizagem no dia a dia de sua atividade. É inegável a incidência de novas possibilidades pedagógicas que surgem com o decorrer dos tempos, e essa ação requer do professor um conhecimento da teoria que poderá subsidiar sua ação pedagógica.

Por fim, é possível afirmar, portanto, que, como já lembrado no início deste estudo, pode se entender que o EAr desenvolve uma ação bastante difícil, especialmente em razão de sua retidão criteriosa e reflexiva, facilitando sempre para o crescimento de estudos inovadores, visando ao aprimoramento dos conhecimentos do cidadão.

\section{REFERÊNCIAS}

BARDIN, L. Análise de conteúdo. São Paulo: Edições 70, 2011, 229 p.

BARDIN, L. L'analyse de contenu. $8^{\text {a }}$ édition corrigée. Paris: Presses Universitaires de France, 1977. $291 \mathrm{p}$.

BARRETO, E. S. de S.; PINTO, R. P. Avaliação da Educação Básica (1990-1998). Estado do Conhecimento $\mathbf{n}^{\mathbf{0}}$. 4. Brasília, DF: MEC/INEP, COMPED, 2001.

BORGES, C. M. F. O professor da educação básica e seus saberes profissionais. Araraquara: JM Editora, 2004.

BRASIL. Lei no 9394/96 de 20 de dezembro de 1996. Lei de Diretrizes e Bases da Educação Nacional (LDBEN). Diário Oficial da República Federativa do Brasil, Brasília, DF, n 248, 23 dez. 1996.

CALDEIRA, A. M. S. Ressignificando a avaliação escolar. In: Comissão Permanente de Avaliação Institucional: UFMG-PAIUB. Belo Horizonte: PROGRAD/UFMG, 2000. p. 122-129 
CALLAI, H. C. A educação geográfica na formação docente: convergências e tensões. In: XV ENDIPE-Encontro Nacional de Didática e Prática de Ensino, 2010, Belo Horizonte. Coleção Didática e Prática de Ensino- Convergências e tensões no campo da formação e do trabalho docente. Anais... Belo Horizonte: Autêntica, 2010. p. 412-433.

CAPES. Qualis Periódicos. Disponível em: <https://sucupira.capes.gov.br/sucupira/public/ consultas/coleta/veiculoPublicacaoQualis/listaConsultaGeralPeriodicos.jsf>. Acesso em: 27 jan 2017.

CAStrogiovanNi, A. C.; CALlAI, H. C.; KAERCHER, N. A. Ensino de geografia. Práticas e Textualizações. Porto Alegre: Mediação, 1999.

CAVALCANTI, L. S. A geografia e a realidade escolar contemporânea: Avanços, caminhos, alternativas. In: I SEMINÁRIO NACIONAL: CURRÍCULO EM MOVIMENTO - Perspectivas Atuais. Anais... Belo Horizonte, novembro de 2010.

CAVALCANTI, L. S. Geografia escolar, formação e práticas docentes: percursos trilhados. In: Conhecimentos escolares e caminhos metodológicos. São Paulo: Xamã, 2012.

FERREIRA, N. S. de A. As pesquisas denominadas "estado da arte". Educação \& Sociedade, Campinas, ano XXIII, nº. 79, p. 257-272, 2002.

FREIRE, Paulo. Extensão ou comunicação. [tradução de Rosisca Darcy de Oliveira]. 12 ed. Rio de Janeiro: Paz e Terra, 2002.

GATTI, B. Formação de professores e carreira: problema e movimentos de renovação. Campinas: Autores Associados, 1997.

HADDAD, S. Juventude e escolarização: uma análise da produção de conhecimentos. Estado do Conhecimento $\mathbf{n}^{\mathbf{0}}$. 8. Brasília, DF: MEC/INEP, COMPED, 2002.

KENSKI, V. M. Educação e Tecnologias: O novo ritmo da informação. Campinas, SP: Papirus, 2007.

LA ROSA, J. Psicologia e educação: o significado do aprender. Porto Alegre: EDIPUCPR, 2003.

LAVILLE, C.; DIONNE, J. A construção do saber. Belo Horizonte: UFMG, 1999. 340 p.

MORAES, A. C. R. Geografia: Pequena História Crítica. 20. ed., São Paulo: Annablume, 2005.

MORAES, R. Uma tempestade de luz: a compreensão possibilitada pela análise textual discursiva. Ciência \& Educação. v. 9, n. 2, p. 191-211. 2003.

PASSINI, E. Y. Alfabetização cartográfica e a aprendizagem em Geografia. São Paulo: Cortez, 2012.

PIMENTA, S. G. (Org.). Saberes pedagógicos e atividade docente. São Paulo: Cortes, 1999. 
PINHEIRO, A. C. O ensino de Geografia no Brasil: catálogo de dissertações e teses. Goiânia: Vieira, 2005.

SALVI, R. F. A importância da compreensão da circularidade que envolve o processo metodológico da pesquisa qualitativa. In: BATISTA, T. de L.; SALVI, R. F. (orgs.) Pós-Graduação em Ensino de Ciências e Educação Matemática (um perfil de pesquisas). 1. ed. Londrina - PR: EDUEL, 2009. P. 167-181.

SANTOS, A. R. J.; CASALI, A. M. D. Currículo e educação: origens, tendências e perspectivas na sociedade contemporânea. Olhar de professor, Ponta Grossa, 12(2), 2009, 207-231.

SANTOS, M. Espaço e Método. São Paulo: Nobel, 1985.

SILVA, T. T. da. Identidades terminais: as transformações na política da pedagogia e na pedagogia da política. Petrópolis: Vozes, 1996.

SOUZA, S. E. O uso de recursos didáticos no ensino escolar. I Encontro de Pesquisa em Educação, IV Jornada de Prática de Ensino, XIII Semana de Pedagogia da UEM: "Infância e Práticas Educativas”. Arq Mudi. Anais... Maringá, 2007.

TARDIF, M. Saberes docentes e formação profissional. 2. ed. Petrópolis: Vozes, 2002.

ZABALA, A. A Prática Educativa: como ensinar. Porto Alegre: ArtMed, 1998. 